\title{
Comparing Life Cycle Assessment (LCA) of Salmonid Aquaculture Production Systems: Status and Perspectives
}

\author{
Gaspard Philis ${ }^{1, *(\mathbb{D}}$, Friederike Ziegler $\left.{ }^{2} \mathbb{(}\right)$, Lars Christian Gansel ${ }^{1}$, Mona Dverdal Jansen ${ }^{3}(\mathbb{D}$, \\ Erik Olav Gracey ${ }^{4}$ and Anne Stene ${ }^{1}$ \\ 1 Department of Biological Sciences, Norwegian University of Science and Technology, Larsgårdsvegen 2, \\ 6009 Ålesund, Norway; lars.gansel@ntnu.no (L.C.G.); anne.stene@ntnu.no (A.S.) \\ 2 Agrifood and Bioscience, RISE Research Institutes of Sweden, Post box 5401, 40229 Gothenburg, Sweden; \\ friederike.ziegler@ri.se \\ 3 Section for Epidemiology, Norwegian Veterinary Institute, Pb 750 Sentrum, 0106 Oslo, Norway; \\ mona-dverdal.jansen@vetinst.no \\ 4 Sustainability Department, BioMar Group, Havnegata 9, 7010 Trondheim, Norway; erigr@biomar.com \\ * Correspondence: gaspard.philis@ntnu.no; Tel.: +47-451-87-634
}

Received: 31 March 2019; Accepted: 27 April 2019; Published: 30 April 2019

check for updates

\begin{abstract}
Aquaculture is the fastest growing food sector worldwide, mostly driven by a steadily increasing protein demand. In response to growing ecological concerns, life cycle assessment (LCA) emerged as a key environmental tool to measure the impacts of various production systems, including aquaculture. In this review, we focused on farmed salmonids to perform an in-depth analysis, investigating methodologies and comparing results of LCA studies of this finfish family in relation to species and production technologies. Identifying the environmental strengths and weaknesses of salmonid production technologies is central to ensure that industrial actors and policymakers make informed choices to take the production of this important marine livestock to a more sustainable path. Three critical aspects of salmonid LCAs were studied based on 24 articles and reports: (1) Methodological application, (2) construction of inventories, and (3) comparison of production technologies across studies. Our first assessment provides an overview and compares important methodological choices. The second analysis maps the main foreground and background data sources, as well as the state of process inclusion and exclusion. In the third section, a first attempt to compare life cycle impact assessment (LCIA) and feed conversion ratio (FCR) data across production technologies was conducted using a single factor statistical protocol. Overall, findings suggested a lack of methodological completeness and reporting in the literature and demonstrated that inventories suffered from incomplete description and partial disclosure. Our attempt to compare LCA results across studies was challenging due to confounding factors and poor data availability, but useful as a first step in highlighting the importance of production technology for salmonids. In groups where the data was robust enough for statistical comparison, both differences and mean equalities were identified, allowing ranking of technology clusters based on their average scores. We statistically demonstrated that sea-based systems outperform land-based technology in terms of energy demand and that sea-based systems have a generally higher FCR than land-based ones. Cross-study analytics also strongly suggest that open systems generate on average more eutrophying emissions than closed designs. We further discuss how to overcome bottlenecks currently hampering such LCA meta-analysis. Arguments are made in favor of further developing cross-study LCA analysis, particularly by increasing the number of salmonid LCA available (to improve sample sizes) and by reforming in-depth LCA practices to enable full reproducibility and greater access to inventory data.
\end{abstract}


Keywords: LCA; life cycle assessment; environmental impacts; aquaculture; salmon; trout; production systems; review; cross-study comparison

\section{Introduction}

Population growth, dietary shifts and resource challenges in capture fisheries and agriculture are driving the development of aquaculture production systems worldwide [1]. By 2050, the global population is expected to reach 9.8 billion [2], and robust economic growth in developing nations is expected to lead to a dietary shift towards higher consumption of meat and dairy [3]. These commodities are known to carry a high environmental burden [4]. While one can hardly argue that social development is negative, population growth and higher affluence are expected to generate additional pressure on fragile ecosystems already severely threatened by a variety of adverse human impacts [5]. Current intensive and linear production systems of food, feed, fiber, and bioenergy are largely exceeding the earth's capacity to regenerate the consumed biomass, exposing our societies to serious environmental and food security risks in the long run [6]. Global food production cannot continue to depend on agriculture and capture fisheries to the same degree in the future. Fisheries have been stagnating since the 1990s, constrained by the natural production limits of wild populations [7]. Meanwhile, agricultural systems are facing various challenges including decreasing soil fertility and arable land availability $[8,9]$.

Aquaculture is one of the most efficient food production systems the world will rely upon to meet tomorrows demand for animal-sourced foods and reduce current environmental impacts associated with the supply of animal protein $[1,10]$. Since the 1980s, one of the largest developments in aquaculture has been driven by carnivorous salmonids, especially Atlantic salmon (Salmo salar), rainbow trout (Oncorhynchus mykiss), and coho salmon (Oncorhynchus kisutch). Salmonid aquaculture is central to the global seafood landscape since it alone accounts for $18.1 \%$ of the value and $7.4 \%$ of the biomass of the world trade in fish and fish products [1]. This production is especially important in Northern Europe (Norway, Ireland, Scotland, Faroe Islands, Iceland) and North and South America (Chile andCanada), in countries with abundant access to cold/temperate marine waters and extensive coastlines. Salmonids are primarily consumed in the United States, Europe, and East Asia. While consumption growth slows down in these traditional markets (but remain positive), consumption is now increasing the most in emerging markets such as Southeast Asia and Latin America [11]. Salmonid species are particularly appreciated for their taste, reddish-orange colored fillets, high-quality proteins, and their marine omega-3 fatty acids content $[12,13]$. Farmed salmon are also considered a sustainable alternative to terrestrial meat producing species, including beef cattle, hogs, and broiler chickens $[14,15]$. Salmonids are efficient livestock with low energy expenditure due to their cold-blooded homeostasis physiology and the gravitational constraints opposed by buoyancy under water [16,17]. Yet, despite these favorable characteristics, salmonid aquaculture faces a variety of environmental challenges. While aquaculture production addresses some of the issues of current food systems by using efficient marine livestock and (partly) moving production at sea, it does not address the underlying challenges of intensive and linear systems (inherited from agricultural practices). Future production increases will hinge on the industry's ability to solve challenges posed by parasites, diseases, nutrient emissions, and critical feed resource scarcity [18-20], among others. For instance, in Norway, the aquaculture industry has ambitions to increase salmonid production fivefold by 2050; however, it is increasingly clear that such a target cannot be achieved without identifying and addressing the underlying environmental issues of existing open sea-based systems [21].

Life cycle assessment (LCA) is one of the environmental accounting tools that can be used to provide the critical information necessary to improve the sustainability of such aquaculture systems. During the last 20 years, the emergence of LCA as a standardized method to measure the environmental impacts of products and services enabled researchers to assess complex seafood systems and provide 
sustainability guidelines to the industry and policymakers [22-24]. Since salmonids are one of the most high-value types of aquaculture species produced worldwide [1], and the interest to increase production volumes is high, this finfish type is the most studied species group in the aquaculture LCA literature. In fact, it is the only group for which LCA studies exist for various species, countries, feed recipes, and production technologies. LCA has been employed to compare products with similar functions [25], measure differences between feed formulations [26,27], and to evaluate the environmental efficiency of trout [28-30], and salmon [31-33]. Within this species group, the LCA methodology has also been employed repeatedly to compare the environmental impact of existing and emerging production technologies [34-36].

Following the accumulation of aquaculture LCA studies, several reviews recently analyzed this section of the literature, focusing on the application of the LCA methodology [37-39] and comparing production systems [40-43]. In the latter ones, attempts to compare results focused primarily on the comparison of the system's intensities (intensive, semi-intensive, and extensive) and culture types (polyculture vs. monoculture). Overall, the authors strictly avoided cross-study single factor statistical comparisons, because LCA data are known to be subject to a wide range of intricate influential variables. The scoping of this review has a sensitive balance, since a broad scope increases sample sizes and the influence of confounding factors, while a narrow one reduces discrepancies and the number of data points available. While previous reviews in this field focused on the whole aquaculture sector, we believe farmed salmonids to be a suitable species group to do an in-depth, comprehensive literature review. Such a scope allows us to study how different production systems for similar species with similar requirements compare, and if such LCA comparisons are meaningful. We consequently analyzed three key features of current salmonid LCAs. Firstly, we provide an overview and compare methodological choices. The objective is to evaluate common methodological practices, identify shortcomings, and suggest recommendations to practitioners. Secondly, we map and compare the inventory and modeling protocol of each study. We strive to identify the strengths and weaknesses of models and datasets used in publications. Thirdly, we perform a cross-study analysis on the life cycle impact assessment (LCIA) and FCR results through the prism of production technologies. Within this third analysis, we are making a first attempt to perform a cross-study statistical comparison of LCIA and FCR scores. This statistical protocol voluntarily ignores confounding factors to specifically investigate if LCA results comparisons can be performed on relatively homogenous samples (similar salmonid species) despite the influence of other variables. With this, our objectives are to assess if overarching statistical differences between groups can be identified, if discrepancies between studies are simply too great to validate such comparisons, and if LCA methodological developments are required to enable more direct comparability.

\section{Materials and Methods}

\subsection{Study Selection}

A systematic analysis of 24 LCA studies (20 peer-reviewed articles and four gray literature research) based on salmonid aquaculture systems was performed in this review (Table 1). The systems assessed produced Atlantic salmon (Salmo salar), rainbow trout (Oncorhynchus mykiss), Arctic char (Salvelinus alpinus), Chinook salmon (Oncorhynchus tshawytscha), brook trout (Salvelinus fontinalis), and brown trout (Salmo trutta fario). All of these species are classified under the Salmonidae family. Article identification was performed using the online search engines of Science Direct, Web of Science, Google Scholar, and Google. The keywords used were a combination of "LCA", "life cycle assessment", "aquaculture", "farmed salmon", "trout", "rainbow trout", and "marine products." The timespan ranged from 2000 to 2018. We identified 355 studies of interest. Primary refinement focused on titles and abstracts, with "environmental assessment" and "aquaculture system" as the selection criteria to isolate 65 publications. Secondary refinement concentrated on methods and models to select research focusing on salmonid aquaculture systems and containing original LCA case studies, resulting in the 
final selection of 24 assessments (Section 2.1.1, "article selection", supplementary data). A study was deemed original when significant first-hand data collection of at least one of the main foreground processes (hatchery and grow-out) took place. Five studies qualifying for selection were excluded. The inventories of Buchspies et al. [44], Ytrestøyl et al. [45], and Hall et al. [46] revealed an absence of original data. Winther et al. [47] was excluded in favor of Ziegler et al. [48] since both are presenting the same data/results and the latter is a peer-reviewed publication. Samuel-Fitwi et al. [49] was removed from the list in favor of Samuel-Fitwi et al. [50] since both studies were built with the same dataset and the latter assessed different production technologies (Section 2.1.2, "study exclusion", supplementary data).

\subsection{Analytical Procedure}

This work was articulated around three main analytical sections: (1) The specific choices related to LCA methodology, (2) the construction of life cycle inventories, and (3) a cross-study technological comparison based on compiled LCIA and FCR results (Section 2.2.1, "scope of the review", supplementary data). All analyses were performed in Excel. The first section presented the main methodological choices made by LCA practitioners. This encompassed mapping and comparing selections of functional units (FU), system boundaries, characterization methods, characterization factors, multi-functionality, as well as checking for the inclusion of interpretation tools such as contribution, sensitivity, and uncertainty analyses.

Table 1. List of articles and reports selected for review.

\begin{tabular}{|c|c|c|c|}
\hline ID & Author and Year & Topic & Organization \\
\hline 1 & Aubin et al. [51] & Carnivorous finfish production systems & INRA $^{a}$ \\
\hline 2 & Avadi et al. [30] & Artisanal vs. commercial Peruvian feed & INRA $^{a}$ \\
\hline 3 & Ayer et al. [52] & Comparison of copper and nylon net-pens & EarthShift Global ${ }^{\mathrm{b}}$ \\
\hline 4 & Ayer and Tyedmers [34] & Culture systems in Canada & Jacques Witford ${ }^{c}$ \\
\hline 5 & Boissy et al. [29] & Impacts of plant-based salmonid diets & Montpellier U \\
\hline 6 & Chen et al. [28] & Trout farming in France & INRA $^{a}$ \\
\hline 7 & D'Orbcastel et al. [53] & Comparison of two trout systems & IFREMER ${ }^{\mathrm{d}}$ \\
\hline 8 & Dekamin et al. [54] & Rainbow trout production in Iran & $\mathrm{UMA}^{\mathrm{e}}$ \\
\hline 9 & Ellingsen and Aanon. [25] & Comparison of wild cod, farmed salmon, and chicken & SINTEF $^{f}$ \\
\hline 10 & Grönroos et al. [36] & Finnish cultivated rainbow trout & SYKE $g$ \\
\hline 11 & Hognes et al. [32]* & Norwegian salmon production & SINTEF $^{\mathrm{f}}$ \\
\hline 12 & Liu et al. [35] & Carbon footprint of two farming models for salmon & SINTEF $\mathrm{f}$ \\
\hline 13 & McGrath et al. [33] & Novel close aquaculture salmon technology & Dalhousie U \\
\hline 14 & Newton and Little [55] & Farmed Scottish salmon & Stirling U \\
\hline 15 & Nyhus [56]* & Comparing salmon closed and open cage system & NTNU $^{\text {h }}$ \\
\hline 16 & Papatryphon et al. [24]* & Trout farming in France & INRA $^{\text {a }}$ \\
\hline 17 & Parker [57] & Implications of high animal by-product feed inputs & British Colum. U \\
\hline 18 & Pelletier et al. [31] & Global salmon farming systems & Dalhousie U \\
\hline 19 & Samuel-Fitwi et al. [50] & Raising rainbow trout in different systems & GMA $^{\mathrm{i}}$ \\
\hline 20 & Silvenius et al. [58] & Climate and eutrophication impact of Finnish trout & LUKE $^{j}$ \\
\hline 21 & Smárason et al. [27] & Icelandic arctic char fed three different feeds & Matis ${ }^{k}$ \\
\hline 22 & White [59] * & Efficiency of the Tasmanian salmon industry & Bond $\mathrm{U}$ \\
\hline 23 & Wilfart et al. [60] & Accounting of aquaculture systems & INRA ${ }^{a}$ \\
\hline 24 & Ziegler et al. [48] & Carbon footprint of Norwegian seafood products & $\mathrm{SIK}^{1}$ \\
\hline
\end{tabular}

${ }^{\mathrm{a}}$ INRA = National Institute for Agricultural Research; ${ }^{\mathrm{b}}$ EarthShift Global = sustainability consultancy company; ${ }^{\mathrm{c}}$ Jacques Witford = environmental consulting engineering company; ${ }^{\mathrm{d}}$ IFREMER = French Research Institute for the Exploitation of the Sea; ${ }^{\mathrm{e}} \mathrm{UMA}=$ University of Mohaghegh Ardabili; ${ }^{\mathrm{f}}$ SINTEF $=$ The Company for Industrial and Technical Research; ${ }^{\mathrm{g}} \mathrm{SYKE}=$ Finnish Environmental Institute; ${ }^{\mathrm{h}} \mathrm{NTNU}=$ Norwegian University of Science and Technology; ${ }^{i}$ GMA = Society for Marine Aquaculture; ${ }^{j}$ LUKE = Natural Resource Institute Finland; ${ }^{\mathrm{k}}$ Matis = Icelandic food and biotechnology R\&D institute; ${ }^{1} \mathrm{SIK}=$ Swedish Institute for Food and Biotechnology; and $\mathrm{U}=$ University. ${ }^{*}$ Non-peer reviewed reports.

The second section measured and compared the data quality of inventories by reviewing the main foreground and background sources used by authors. We also estimated study completeness by mapping process inclusion and exclusion, including an evaluation of the LCA practitioner reporting 
practices. In this analysis, the literature was divided into two groups: Trout and salmon systems. This separation was performed to highlight significant inventory differences between the trout and salmon LCAs, and its application was strictly limited to this section. Overall, 14 independent processes were identified to fully cover the life cycle of salmonids (Table 2).

In the third section, LCIA and key inventory data in terms of FCR results were compared across studies according to their production technology. Although FCR scores are LCI data and as such differ significantly in nature from LCIA results, we found it meaningful to add this parameter to the analysis. The FCR indicates the quantity of feed use per unit of fish produced, and although it has been criticized lately in cross-species efficiency comparison [61], we estimated this parameter to be representative of the overall efficiency of salmonid production systems. It is also a parameter directly linked to the aquafeed process, which is by far the largest contributing component to the life cycle emissions of salmonids [51,54,57]. FCR has recently been identified as a useful indicator to follow up environmental performance in farmed aquaculture within a species and using the same feed [62]. While it was not possible to standardize feed compositions across studies due to a lack of inventory disclosure, our comparison dealt with species of the same family, with similar nutrient requirements to enhance comparability of FCRs. For the LCIA data, the comparison was performed for the four most commonly used impact categories in the reviewed studies: Global warming potential (GWP), acidification potential (AP), eutrophication potential (EP), and cumulative energy demand (CED). Out of the 24 LCA studies selected, a total of 67 scenarios were identified. These LCA scenarios have variable focus, among others investigating impacts of different feed composition, electricity mix, or cage structure. Scenarios were selected based on their production technologies. Scenarios outside the scope of this review were excluded. When scenarios used similar production technology and only the cofounding factor differed, results were averaged. After selection, 35 scenarios remained for GWP, 30 for AP, 29 for EP, and 24 for CED. Of those scenarios, 33 disclosed their FCR scores, which were subsequently used in this analysis (Section 2.2.2, "LCIA scenario selection", supplementary data).

Table 2. List of salmon and trout life cycle processes.

\begin{tabular}{cc}
\hline Process & Process Description \\
\hline Energy carrier & All energy carriers required through the life cycle (e.g., electricity, gas) \\
Transport & All transports required through the life cycle, without distribution (e.g., lorry, shipping) \\
Chemotherapeutant & Includes chemicals, disinfectants, and veterinary products \\
Equipment & Supply considered having a lifetime ranging from 1 to 10 years \\
Infrastructure & Supply considered having a lifetime greater than 10 years \\
Feed production & Agricultural and fishery ingredients, and their transformation into aquafeed \\
Egg production & Selection, and reproduction of broodstock for egg production \\
Hatchery & Grow-out of eggs into 70 g large juvenile fish \\
Fish production & Grow-out of juveniles into $4-5$ kg adult fish \\
Effluent & Emissions of feces, urine, and feed waste generated during grow-out \\
Effluent treatment & Treatment of hatchery and fish production effluents \\
Infrastructure EOL & Dismantling and waste treatment of farms infrastructure \\
Processing & Processing of live fish into HOG or filleted fishes \\
Distribution & Transport and retail of HOG or filleted fishes from processing to customers \\
\hline
\end{tabular}

While the comparability of LCIA results is uncertain due to the wide range of diverging parameters existing between studies (e.g., year, country, production site, feed composition, characterization method, assumption, etc.), we increased consistency by only comparing cradle-to-gate systems producing $1 \mathrm{t}$ live-weight salmonids. Most studies already expressed their results in this format. Six studies used different system boundary and FU combinations $[35,36,48,52,55,58]$. We performed a small system boundary adjustment of Ayer et al. [52] by adding hatchery impacts using contribution analysis results from Pelletier et al. [31]. Cradle-to-farm gate impacts of $1 \mathrm{t} \mathrm{FU}$ produced were available in Liu et al. [35] and Ziegler et al. [48] and part of the secondary results. Newton and Little [55], Silvenius et al. [58], and Grönroos et al. [36] adjusted impacts were obtained through personal communication with the authors. Grönroos et al. [36] adjusted results differ significantly from the 
published results due to an inventory error discovered by the authors (Section 2.2.3, "adjustment calculations", supplementary data).

All scenarios were separated into four production technology clusters. Salmonid aquaculture production technologies revolve around two major characteristics: Sea-based vs. land-based (clusters A-B) and open vs. closed (clusters C-D) systems. This led us to the selection of four-production technology clusters: (1) Closed sea-based systems, (2) open land-based systems, (3) open sea-based systems, and (4) closed land-based systems. Cluster (1) contains experimental pilots of either a solid wall aquaculture system [33,56] or marine floating bag [34,36]. These systems provide a controlled production environment at sea and a form of waste collection. Cluster (2) exclusively gathers flow-through aquaculture system (FTAS) technology. Such raceways usually divert flowing water (often from rivers using gravity) through successive concrete flumes before discharging back to the water body [63]. While this is mostly a freshwater system used for rainbow trout production, a few studies also investigated the production of salmon and char using marine and brackish waters $[27,34]$. Cluster (3) is the most common form of salmon production, usually taking place in net pens of various sizes and forms (mostly circular). In open cages, only nets separate the biomass from the environment, which means that salmonid metabolites and extra feed pellets are directly emitted to the surrounding waters [64]. Cluster (4) is mostly recirculating aquaculture system (RAS) technology. This land-based design uses circular tanks to produce trout, char, and salmon, primarily in freshwater conditions. Water movement and oxygenation is insured by machinery and is recycled using drum and bio-filters [65].

\subsection{Statistical Analysis}

A statistical analysis of each production clusters for LCIA and FCR scores was performed in SPSS v24 (IBM Corp, Armonk, New York, United States). In this review, we deliberately opted for a single parametric statistical protocol to compare the means of the different technological clusters. This is a first attempt to make a statistical LCA cross-study comparison without involving multifactorial analysis to investigate if a simpler, non-discriminant, comparative protocol can be applied to identify overarching trends in LCA results. We are not trying to compare the groups independent of confounding factors, but to investigate if current LCA data can be statistically compared despite them. The equivalent non-parametric test to ANOVA (Kruskal-Wallis) was disqualified due to heterogeneous distributions in the data. The LCIA and FCR data was analyzed following a four-group comparison (clusters 1 to 4), and two subsequent two-group comparison testing data of clusters A-B and C-D (Figure 1). Throughout the analysis, the significance level $\alpha$ (referring to the probability of making a type one error) was set to $5 \%$. An identical test protocol was applied to all data. Each group was tested for normality with Shapiro-Wilk and homogeneity of variances using a Levene's test. For Shapiro-Wilk, $p$-values were tested against the null hypothesis, assuming a normal distribution within clusters, while for Levene's test, the null hypothesis was supporting similar group variances. If homogeneity of variance was achieved, a one-way ANOVA t-test was used to compare the means of clusters. Where variances were found to be statistically different, a Welch t-test was performed to compare the homogeneity of the means. If the Welch-test indicated a statistically significant difference between some of the means, the Games-Howell post hoc test was performed to identify which of the cluster's means were different from one another. Results of both the ANOVA and Welch t-test were rejected if the group involved displayed were skewed. For these three statistical tests, the null hypotheses assume means equality. 


\begin{tabular}{|c|c|c|c|c|c|}
\hline \multirow[b]{2}{*}{ 4-group comparison } & \multicolumn{4}{|c|}{ LCIA Statistical Analysis } & \multirow{2}{*}{$\frac{\text { FCR Statistical Analysis }}{\text { FCR }}$} \\
\hline & GWP & $\mathrm{AP}$ & EP & CED & \\
\hline Cluster $1 \rightarrow$ closed, sea-based & 4 & 4 & 3 & 3 & 4 \\
\hline Cluster $2 \rightarrow$ open, land-based & 9 & 9 & 9 & 9 & 8 \\
\hline Cluster $3 \rightarrow$ open, sea-based & 15 & 11 & 11 & 10 & 14 \\
\hline Cluster $4 \rightarrow$ closed, land-based & 7 & 6 & 6 & 4 & 7 \\
\hline \multirow{3}{*}{$\begin{array}{l}\text { Cluster A } \rightarrow \text { sea-based } \\
\text { Cluster B } \rightarrow \text { land-based }\end{array}$} & & & & & \\
\hline & 19 & 15 & 14 & 13 & 18 \\
\hline & 16 & 15 & 15 & 11 & 15 \\
\hline \multirow[t]{3}{*}{ 2-group comparison (C-D) } & & & & & \\
\hline & 24 & 20 & 20 & 17 & 22 \\
\hline & 11 & 10 & 9 & 7 & 11 \\
\hline
\end{tabular}

Figure 1. Structure of the life cycle impact assessment (LCIA) and feed conversion ratio (FCR) statistical analysis displaying the numbers of data points per clusters.

\section{Results}

\subsection{Methodology Analysis}

The location of the production systems reflects the current dominance of salmonid aquaculture by a handful of industrialized countries; Norway, the United Kingdom, Canada, Chile, and Australia dominate salmon production, while Finland and France concentrate on trout species. Dealing with multi-functionality remains controversial and heterogeneous, with practitioners using a mix of mass, economic, and energy-based allocation throughout the literature (Table 3). System expansion, recommended by ISO 14040 [66], is rarely employed. All studies follow the attributional LCA framework, except for Samuel-Fitwi et al. [50], employing the consequential approach. Out of the 24 studies reviewed, 20 are using different versions of SimaPro (PRé Sustainability, Amersfoort, the Netherlands) for modeling and calculations. CML-IA remains the most common characterization method (applied 14 times), followed by the ReCiPe midpoint framework (applied five times). All studies provide a process-based contribution analysis, and most of them include a sensitivity analysis to test for critical data sources and/or methodological choices. Only four studies $[30,33,52,54]$ included an uncertainty analysis.

The range of midpoint impact categories selected is widespread across studies. GWP, EP, AP, and CED are by far the most represented categories with application rates of respectively $100 \%, 87 \%$, $78 \%$, and $61 \%$. Characterization factors used to calculate these midpoint scores evolve over time, but are mostly (in frequency) based on the work of IPCC [67], Heijungs et al. [68], Huijbregts [69], Frischknecht [70], and Frischknecht et al. [71]. LCA practitioners often add biotic resource use (43\%), water dependence (43\%), and land occupation (39\%) to measure additional impacts significant for salmonid aquaculture production. Results show strong discrepancies between the characterization methods, the characterization factors and their application by authors. For example, in CML-IA, the EP characterization factors (based on Heijungs et al. [68]) refer to phosphorus (kg PO4-e) without discerning marine and freshwater nutrient limitation, while ReCiPe expresses the same impacts based on nitrogen ( $\mathrm{kg} \mathrm{N}-\mathrm{e}$ ) and phosphorus ( $\mathrm{kg} \mathrm{P}$-e) depending on the emissions medium [72]. In different studies, water dependence is also named water depletion [30], water use [29,59], freshwater footprint [32], and consumptive water use [55]. Land occupation is inconsistent in both naming and units between studies. 
Table 3. Main methodological choices used in salmonids life cycle assessment (LCA).

\begin{tabular}{|c|c|c|c|c|c|c|c|c|}
\hline \multirow{2}{*}{ ID } & \multicolumn{4}{|c|}{ Goal and Scope Definition } & \multicolumn{4}{|c|}{ LCIA/Interpretation } \\
\hline & Functional Unit & Location & System Boundaries & Multi-functionality & CM & CA & SA & UA \\
\hline 1 & $1 \mathrm{t}$ LW Rainbow Trout & France & Farm to farm & $\mathrm{NA}$ & CML-IA & $\boldsymbol{v}$ & $\boldsymbol{v}$ & \\
\hline 2 & $1 \mathrm{t}$ LW Rainbow Trout & Peru & Cradle to farm & Energy allocation & CML-IA/ReCiPe & $\boldsymbol{v}$ & $\checkmark$ & $\boldsymbol{v}$ \\
\hline 3 & $1 \mathrm{t} \mathrm{LW}$ Atlantic Salmon & Chile & Farm to farm & Energy allocation & ReCiPe midpoint & $\checkmark$ & $\boldsymbol{v}$ & $\checkmark$ \\
\hline 4 & $1 \mathrm{t}$ LW Atlantic Salmon/Arctic Char & Canada & Cradle to farm & Energy allocation/SE & CML-IA & $\boldsymbol{v}$ & $v$ & \\
\hline 5 & $1 \mathrm{t}$ LW Atlantic Salmon/Rainbow Trout & Scotland/France & Cradle to farm & Economic allocation/MA & CML-IA & $\boldsymbol{v}$ & $\checkmark$ & $\checkmark$ \\
\hline 6 & $1 \mathrm{t}$ LW Rainbow Trout & France & Cradle to farm & Economic allocation & CML-IA & $\checkmark$ & $\checkmark$ & \\
\hline 7 & $1 \mathrm{t}$ LW Trout/Arctic Char & France & Cradle to farm & NA & CML-IA & $\checkmark$ & $\checkmark$ & \\
\hline 8 & $1 \mathrm{t}$ LW Rainbow Trout & Iran & Cradle to farm & NA & CML-IA & $\boldsymbol{v}$ & $\boldsymbol{v}$ & $\checkmark$ \\
\hline 10 & 1 t Un-gutted Rainbow Trout & Finland & Cradle to processing & NA & Finnish factors & $\checkmark$ & & \\
\hline 11 & 1 kg LW Atlantic Salmon & Norway & Cradle to farm & Mass allocation & ReCiPe midpoint & $\checkmark$ & & \\
\hline 12 & $1 \mathrm{~kg}$ HOG Atlantic Salmon & Norway/USA & Cradle to distribution & Mass allocation & NA & $\boldsymbol{v}$ & & \\
\hline 13 & $1 \mathrm{t}$ LW Chinook Salmon & Canada & Cradle to farm & Energy allocation & ReCiPe midpoint & $\boldsymbol{v}$ & $\checkmark$ & $\checkmark$ \\
\hline 14 & $1 \mathrm{t}$ HOG Atlantic Salmon & Scotland & Farm to processing & Economic allocation/MA & CML-IA & $\checkmark$ & $\boldsymbol{v}$ & \\
\hline 15 & $1 \mathrm{t}$ LW Atlantic Salmon & Norway & Cradle to farm & NA & ReCiPe midpoint & $\checkmark$ & $\checkmark$ & \\
\hline 16 & $1 \mathrm{t}$ LW Rainbow Trout & France & Cradle to farm & Economic allocation & CML-IA & $\checkmark$ & & \\
\hline 17 & $1 \mathrm{t}$ LW Atlantic Salmon & Australia & Cradle to farm & Energy allocation/SE & CML-IA & $\checkmark$ & $\checkmark$ & \\
\hline 18 & $1 \mathrm{t}$ LW Atlantic Salmon & NO/UK/Canada/Chile & Cradle to farm & Energy allocation & CML-IA & $\boldsymbol{v}$ & $\checkmark$ & \\
\hline 19 & $1 \mathrm{t}$ LW Rainbow Trout & Germany/Denmark & Cradle to farm & System expansion & CML-IA & $\checkmark$ & $\checkmark$ & \\
\hline 21 & 1 kg LW Arctic Char & Iceland & Cradle to farm & Mass allocation & CML-IA & $\checkmark$ & $\checkmark$ & \\
\hline 22 & 1 t HOG Atlantic Salmon & Australia & Cradle to processing & Mass allocation & CML-IA & $\checkmark$ & $\checkmark$ & \\
\hline 23 & $1 \mathrm{t}$ LW Atlantic Salmon & France & Cradle to farm & Economic allocation & CML-IA & $\checkmark$ & $v$ & \\
\hline 24 & 1 kg HOG Atlantic Salmon & Norway & Cradle to distribution & Mass allocation & Individual factor & $\checkmark$ & $\checkmark$ & \\
\hline
\end{tabular}

Abbreviations: $\mathrm{CA}=$ Contribution Analysis; $\mathrm{CM}=$ Characterization Method; $\mathrm{HOG}=$ Head-On-Gutted; $\mathrm{LW}=$ Live-Weight; $\mathrm{MA}=\mathrm{Mass}$ Allocation; $\mathrm{NA}=$ Not Available; $\mathrm{NO}=$ Norway; SA = Sensitivity Analysis; SE = System Expansion; UA = Uncertainty Analysis; and UK = United Kingdom. 
It is alternatively referred to as agricultural land occupation [30], surface use [53], land use [54,55], and land competition $[50,60]$, and is expressed in square meters per year $[28-30,50,54,55,60]$ or square-meters [53] alternatively. Finally, biotic resource use is also called net primary production in about one-fifth of the studies $[28,29,51,53,59]$ (see supplementary data, Section 3.1.1).

\subsection{Inventory Analysis}

\subsubsection{Trout Production Systems}

First-hand aquaculture data originate primarily from French (Vivier de France SA, Murgat SAS) $[29,51,53]$ and Finnish (Nordic Trout, Rehuraisio Ltd.) $[24,58]$ trout farms. Le Gouessant cooperative [24,51], Marine Harvest [29], Biomar [58], and Cargill [50] are also frequent sources used for aquafeed modeling. Second-hand data covers a broader range of processes and is composed of a multitude of sources. Yet, cross-referencing and recurrent datasets can still be identified. Several practitioners use the data from Agreste [24,28,29] (French agriculture database) as well as Pelletier et al. [31], and Boissy et al. [29] to complete their feed and aquaculture dataset $[28,30,54]$. Various versions of the Ecoinvent database (https://www.ecoinvent.org/) are also used to model agricultural feed ingredients $[29,58]$, as well as transports $[28,30,50]$ and energy carriers $[28,30,50]$. Thrane [73], Schau and Fet [74], and Vázquez-Rowe et al. [75] are occasionally used in Boissy et al. [29] and Fitwi et al. [50] to model impacts from wild fisheries associated with the production of fish meal.

A vast majority of trout studies exclude egg production (broodstock reproduction), effluent treatment, processing, and distribution. Out of 10 studies reviewed, the inclusion frequency of these processes was $30 \%, 40 \%, 20 \%$, and $10 \%$ (Figure 2). Reasons for these exclusions vary from the absence of reliable technology and legislation (e.g., effluent treatment) to the selection of narrower system boundaries (e.g., processing, distribution), and the estimated negligible impacts of a given process (e.g., egg production). None of the trout LCAs included the infrastructure end-of-life (EOL) process because of its versatility and estimated overall low environmental contribution (cut-off criterion). The inclusion of equipment and infrastructure and chemotherapeutants are relatively high, with a use frequency of $70 \%$. Equipment and infrastructure construction of trout systems is intensive since this species is mostly farmed with FTAS and RAS land-based technology. In the literature, the use of chemicals and veterinary products is often reported under the overarching term "chemotherapeutant". However, in practice, this process has an uncertain connotation. In some studies, it refers to chemicals, disinfectants, limestone, and oxygen used in the hatchery and grow-out processes, while in others it also includes veterinary treatments such as antibiotics. Overall, energy carrier, transport, feed production, hatchery, fish production, and effluent are the most common processes (Figure 2). Practitioners expect these processes to have the highest contribution, which makes them less prone to cut-offs, system boundaries, and FU exclusions (see supplementary data, Sections 3.2.1.1 and 3.2.1.2).

\subsubsection{Salmon Production Systems}

Like for trout, first-hand salmon LCA data collections concentrate on fish and feed production and (to a lesser extent) on the hatchery process. In several cases, data from the grow-out phase is confidential and prevent the disclosure of the company's name $[25,31,32,34,35,48,55,57]$. Few studies openly report using grow-out data from Agrimarine Inc [33], Marine Harvest [56], and the companies Tassal, Huon Aquaculture, Petuna, Van Diemen aquaculture, and Saltas [59]. Sources of aquafeed manufacturers are more frequent, with large corporations like Biomar [32,56], Skretting [32,56], Cargill [32,33,56], and smaller firms like Taplow feeds [33], and Ridley [59] being cited more often by name. The spectrum of the second-hand data used in salmon LCA is similar to that for trout. The Ecoinvent database is often used to complete transports [27,31-35,48,52,55-57], energy carriers [27,31,32,34,35,52,55-57], and agricultural feed ingredient [27,32,33,48,56,59] models. In more recent years, the Agri-footprint database (http://www.agri-footprint.com/) has also been used similarly by practitioners, mostly to improve the quality of their aquafeed datasets $[32,35,57]$. Data published 
by Pelletier et al. [31] is cross-referenced throughout the reviewed literature and appear to be central for several aquafeed models [31,33,34,52,56,59]. Like for trout, Thrane [76], Schau and Fet [74], and Tyedmers [77] are sporadically used in Ellingsen and Aanondsen [25], Pelletier et al. [31], and Ziegler et al. [48] to model capture fisheries. In recent work, Parker [57] used Cashion et al. [78] and Parker and Tyedmers [79] to cover similar processes.

Aubin et al. [2000]

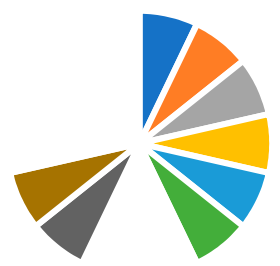

d'Orbcastel et al. [2006]

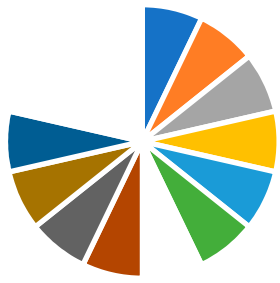

Samuel-Fitwi et al. [N/A]

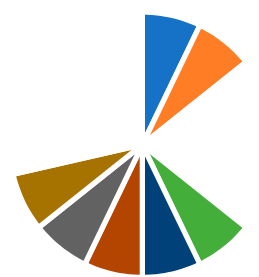

- Energy carrier

- Infrastructure

- Fish production

- Processing
Avadi et al. [2012]

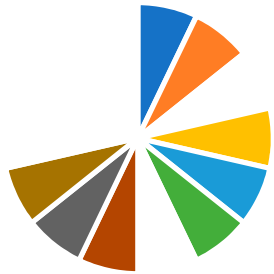

Dekamin et al. [N/A]

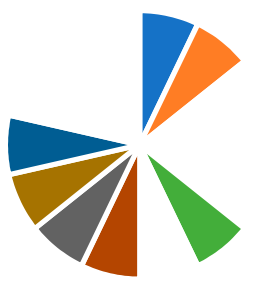

Silvenius et al. [2013]

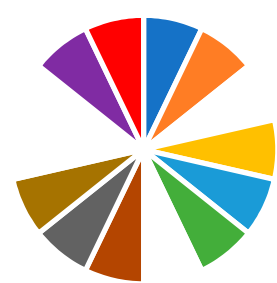

- Transport

- Feed production

- Effluent

- Distribution
Boissy et al. [2008]

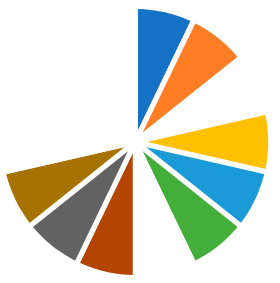

Grönroos et al. [2000]

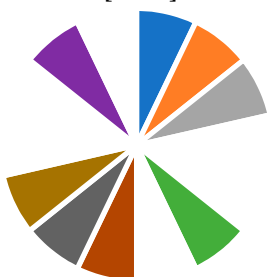

Use frequences

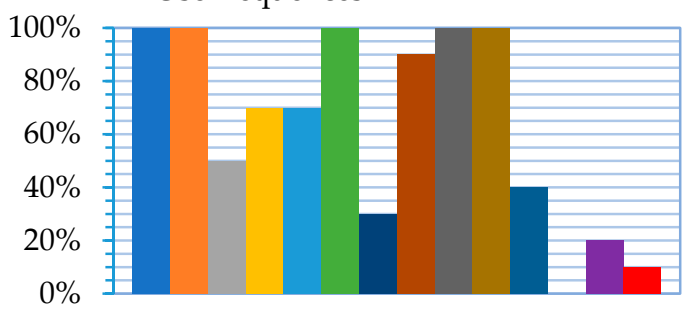

- Chemotherapeutant Equipment

- Egg production - Hatchery

- Effluent treatment Infrastructure EOL

Figure 2. Process inclusion and exclusion in trout LCA studies (data collection dates are placed in brackets).

In the life cycle inventories of salmon LCA models, energy carrier, transport, feed production, hatchery, fish production, and effluent processes have a very high inclusion rate (Figure 3). Only hatchery and effluent are under the $100 \%$ inclusion with $86 \%$ and $79 \%$, respectively. These lower rates can be explained by few process exclusions due to narrower system boundaries (e.g., hatchery) and/or to impact categories selection (e.g., effluent). As such, only carbon footprint studies [32,35,48] excluded effluent since it is estimated not to affect GWP. Chemotherapeutant, equipment, infrastructure, egg production, effluent treatment, infrastructure EOL, processing, and distribution have lower inclusion rates ranging from $7 \%$ to $50 \%$. Here again, processing and distribution directly depend on the study's scope and its system boundaries. Infrastructure EOL is included in Ayer et al. [52] to specifically compare two types of infrastructure through their life cycle (nylon and copper net-pens). Effluent treatments are systematically excluded from open net-pen cages studies but are described by Ayer and Tyedmers [34] and McGrath et al. [33] in the modeling of closed sea-based systems equipped with filters (see supplementary data, Sections 3.2.2.1 and 3.2.2.2). 


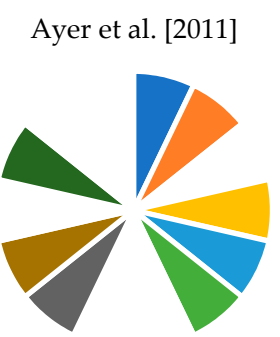

Liu et al. [N/A]

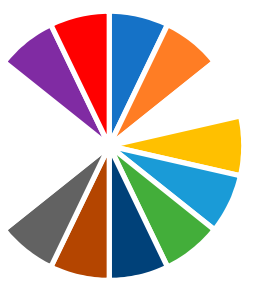

Parker et al. [N/A]

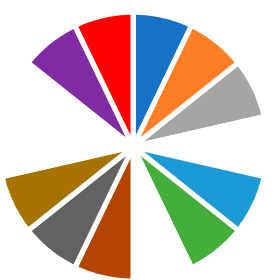

Ziegler et al. [2007]
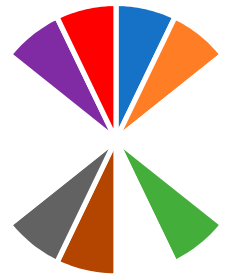

- Energy carrier

- Infrastructure

- Fish production

- Processing

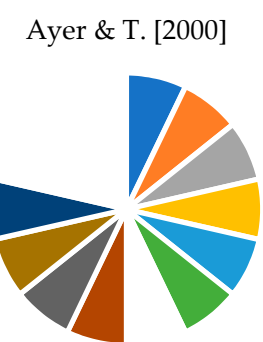

McGrath et al. [2013]

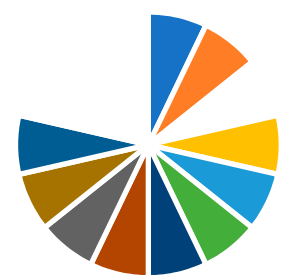

Pelletier et al. [2007]

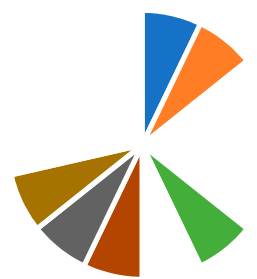

Wilfart et al. [2009]

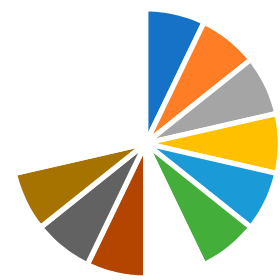

- Transport

- Feed production

- Effluent

- Distribution
Ellingsen \& A. [N/A]

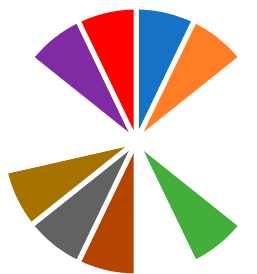

Newton \& L. [2013]

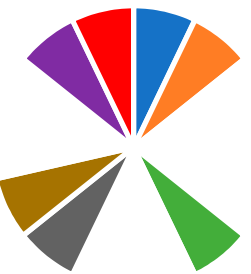

Smárason et al. [2013]

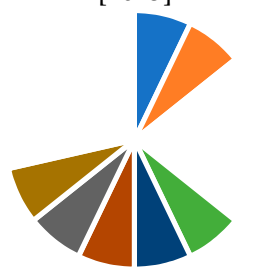

Hognes et al. [2011]

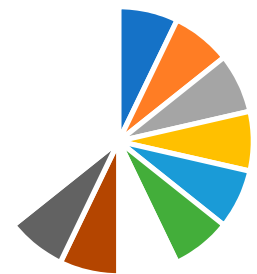

Nyhus [2014]

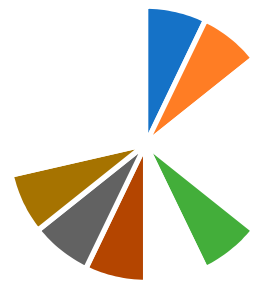

White [2011]

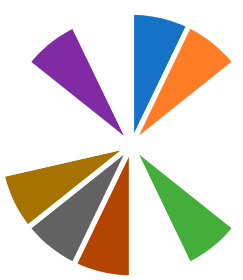

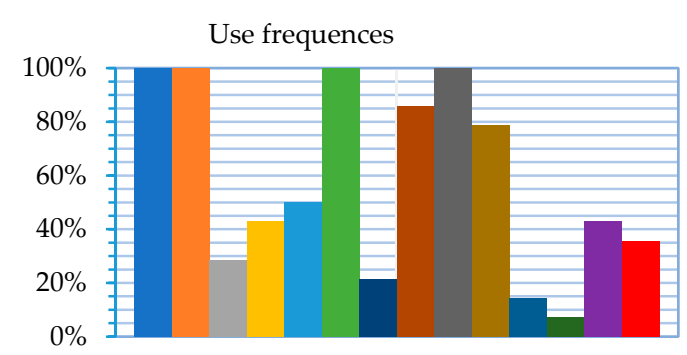

- Chemotherapeutant $\quad$ Equipment

- Egg production $\quad$ Hatchery

- Effluent treatment $\quad$ Infrastructure EOL

Figure 3. Process inclusion and exclusion in salmon LCA studies.

\subsection{Cross-Study Technological Comparison}

\subsubsection{Overview of LCIA and FCR Results}

GWP impacts vary widely across the reviewed literature with a delta between the maximum $\left(13,622 \mathrm{~kg} \mathrm{CO}_{2}\right.$-e) [53] and the minimum (1157 $\mathrm{kg} \mathrm{CO}_{2}$-e) [54] reaching 12,465 $\mathrm{kg} \mathrm{CO}_{2}$-e (Figure 4). Within clusters 1 to 4 , the situation is also heterogeneous with delta scores of respectively 1585; 4252; 7170; and 11,799 $\mathrm{kg} \mathrm{CO}_{2}$-e. Overall, closed sea-based systems perform best with an average score of $2404 \mathrm{~kg} \mathrm{CO}_{2}$-e per ton LW salmonids produced at the farm gate. Open land-based systems rank second with an average impact of $2613 \mathrm{~kg} \mathrm{CO}_{2}$-e while open sea-based and closed land-based systems arrive in 3rd and 4th position with 2933 and as much as $6414 \mathrm{~kg} \mathrm{CO}_{2}$-e for the same production output. FCR values seem to fluctuate independently of climate change impacts (Figure 4).

$\mathrm{AP}$ impacts are also heterogeneous. Grönroos et al. [36] reported as little as $8.8 \mathrm{~kg} \mathrm{SO} \mathrm{SO}_{2}$-e per ton LW trout while Ayer and Tyedmers [34] calculated a score as high as $63.4 \mathrm{~kg} \mathrm{SO}_{2}$-e for a similar 
output (Figure 5). Intra-cluster heterogeneity is comparable to that of climate change impacts. Deltas of $10.1 \mathrm{~kg} \mathrm{SO}_{2}$-e, $23.3 \mathrm{~kg} \mathrm{SO}_{2}$-e, $33.6 \mathrm{~kg} \mathrm{SO}_{2}$-e, and $51.5 \mathrm{~kg} \mathrm{SO}_{2}$-e are observed between minimums and maximums of clusters 1, 2, 3, and 4 respectively. Closed land-based systems perform worst with $26.7 \mathrm{~kg} \mathrm{SO}$-e, while closed sea-based systems outperform all other clusters by generating $15.1 \mathrm{~kg}$ $\mathrm{SO}_{2}$-e per $\mathrm{FU}$ on average. Open land-based and sea-based systems reach the 2nd and 3rd positions with average scores of $16.3 \mathrm{~kg} \mathrm{SO}_{2}$-e and $18.7 \mathrm{~kg} \mathrm{SO}_{2}$-e. Graphic representation of the FCR seems to fluctuate independently of AP impacts scores (Figure 5). For instance, Samuel-Fitwi et al. [50] calculated emissions of $40.7 \mathrm{~kg}$ SO2-e for an FCR of 0.86 while Dekamin et al. [54] reported an FCR of 1.47 with emissions as low as $18.7 \mathrm{~kg} \mathrm{SO} 2-\mathrm{e}$.

Out of $29 \mathrm{EP}$ scores extracted from LCA scenarios, values ranged from $4 \mathrm{~kg}$ [50] to 84 [57] $\mathrm{kg}$ of $\mathrm{PO}_{4}$-e, generating a difference of factor 21 . Results suggested that closed systems perform best, emitting only $17.3 \mathrm{~kg} \mathrm{PO}_{4}$-e (land-based) and 26.7 (sea-based) $\mathrm{kg} \mathrm{PO}_{4}$-e. Open systems generated on average $47.3 \mathrm{~kg} \mathrm{PO}_{4}$-e (sea-based) and 50.6 (land-based) $\mathrm{kg} \mathrm{PO}_{4}$-e into fresh and marine water bodies (Figure 6). Intra-cluster deltas remain high with differences ranging from $30.3 \mathrm{~kg} \mathrm{PO}_{4}$-e, $51.2 \mathrm{~kg} \mathrm{PO}_{4}$-e, and $62.6 \mathrm{~kg} \mathrm{PO}_{4}$-e for systems 4, 2, and 3 respectively. Closed sea-based systems are the exception, displaying a low delta of $8.6 \mathrm{PO}_{4}$-e for this impact category. Any direct correlation between FCR and EP impacts remain widely uncertain with studies displaying both low impacts and high FCR $[34,54]$ as well as low FCR and high impacts [55,57].

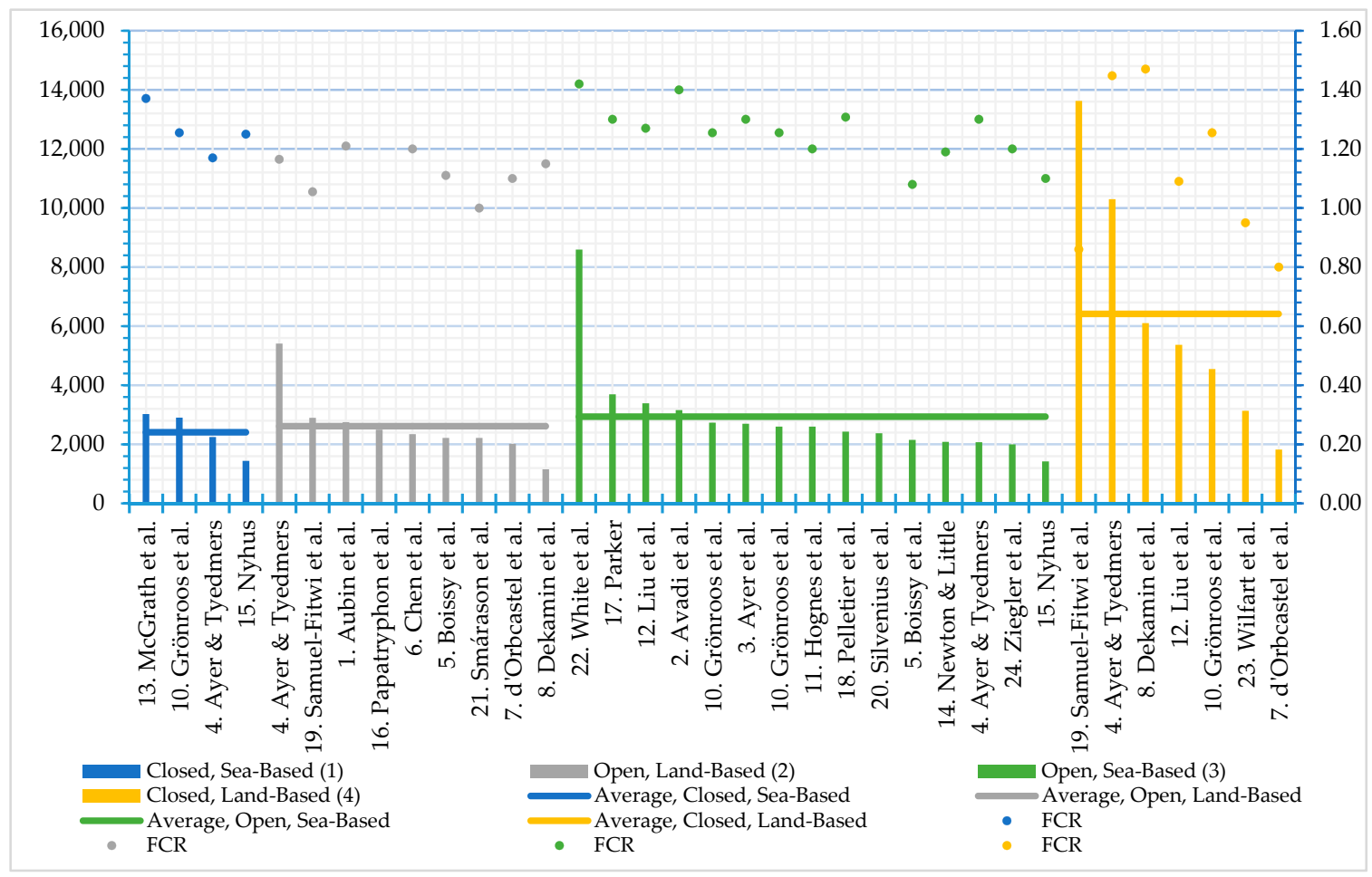

Figure 4. Salmonids global warming potential (GWP) impacts ( $\mathrm{kg} \mathrm{CO} 2-\mathrm{e})$ and FCR based on production technology clusters. 


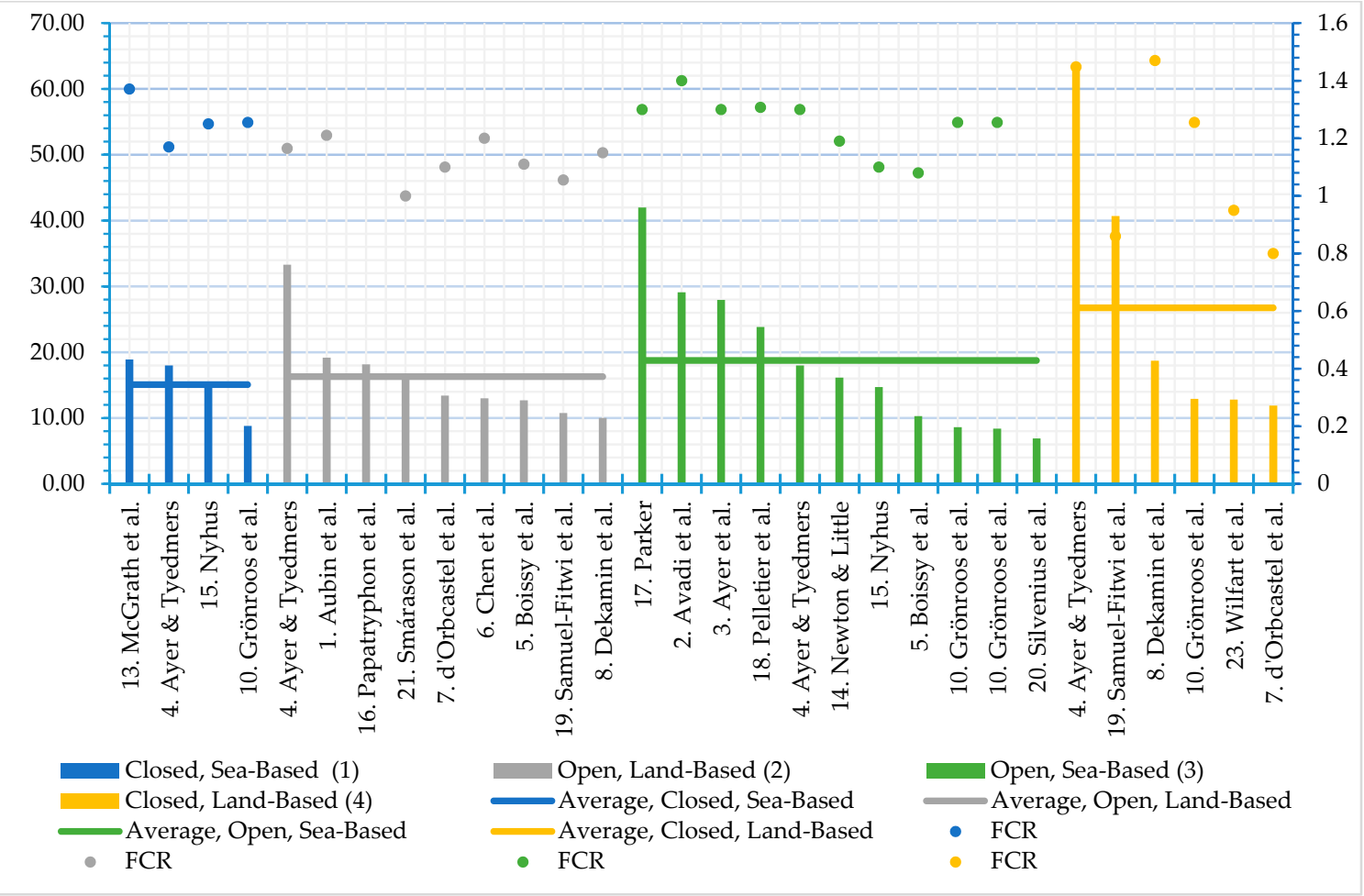

Figure 5. Salmonids acidification potential (AP) impacts (kg SO2-e) and FCR based on production technology clusters.

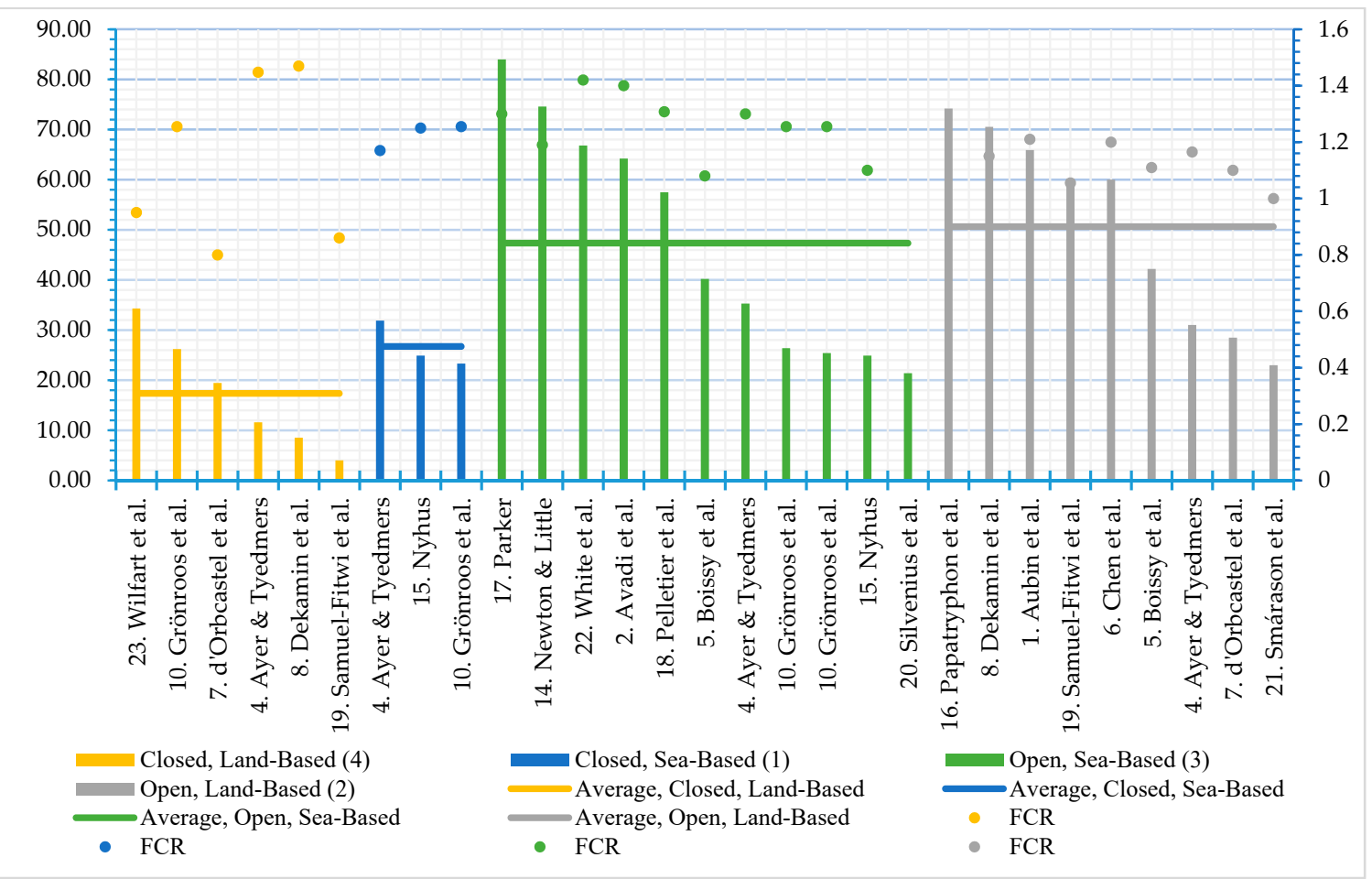

Figure 6. Salmonids eutrophication potential (EP) impacts (kg PO4-e) and FCR based on production technology clusters.

Variability of CED scores is substantial throughout the reviewed literature. The delta for this category represents 206,100 MJ-e, which corresponds to a difference of factor 9.23 between the maximum 
of 233,000 MJ-e [34] and the minimum of 26,900 MJ-e [34] (Figure 7). Intra-cluster impact deltas range from 172,569 to $29,764 \mathrm{MJ}$-e with closed, land-based systems reporting the most variable scores (indicating improvement potential). Closed sea-based systems displayed the most consistent results. Salmonid life cycle CED results show that land-based systems have the highest energy requirements with cluster averages equal to 133,220 MJ-e (closed) and 75,943 MJ-e (open). Sea-based systems, on the other hand, perform best with average CEDs of 37,913 MJ-e (open) and 54,620 MJ-e (closed) per ton LW salmonids produced at the farm gate (Figure 7). Again, a high FCR does not appear to correlate with high CED directly. Studies reporting low FCR and high CED $[27,60]$ and some displaying the inverse relationship $[30,59]$ are commonly found.

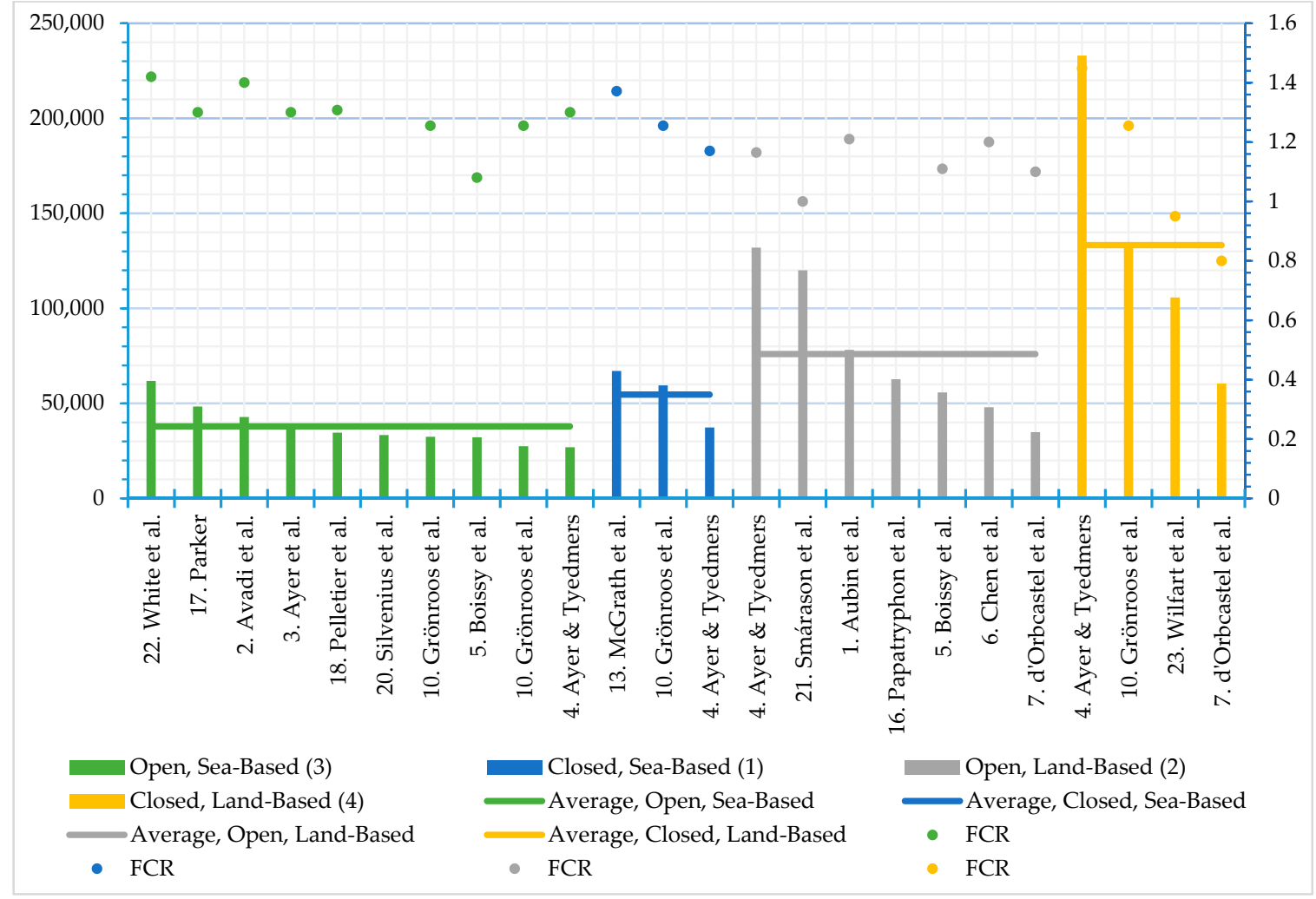

Figure 7. Salmonids cumulative energy demand (CED) impacts (MJ-e) and FCR based on production technology clusters.

The average FCR values of clusters 1, 2, 3, and 4 are 1.262, 1.124, 1.256, and 1.125, respectively for GWP. While FCR fluctuates slightly across impact categories due to differences in sample sizes, results consistently show that open and closed land-based clusters have the lowest average FCR with scores ranging between 1.124-1.131 and 1.113-1.131 and that closed sea-based and land-based technologies oscillate in the upper range within intervals of 1.225-1.265 and 1.249-1.291 (Table 4). Since FCR averages variations between impact categories are minimal and only imputable to sample size, the sub sequential statistical four-groups and two-groups analysis of FCR averages were performed independently of impact categories variations, on the single largest sample size available (also corresponding to the FCR GWP group). 
Table 4. Overview of clusters average FCR for each impact categories.

\begin{tabular}{cccccc}
\hline Cluster & Technology & FCR (GWP) & FCR (AP) & FCR (EP) & FCR (CED) \\
\hline 1 & Closed, Sea-Based & 1.262 & 1.262 & 1.225 & 1.265 \\
2 & Open, Land-Based & 1.124 & 1.124 & 1.124 & 1.131 \\
3 & Open, Sea-Based & 1.256 & 1.249 & 1.261 & 1.291 \\
4 & Closed, Land-Based & 1.125 & 1.131 & 1.131 & 1.113 \\
\hline
\end{tabular}

\subsubsection{Statistical Comparison of LCIA and FCR Results}

\section{(a) Four-Groups Analyses}

Out of the 16 LCIA groups (Figure 1), cluster 2-3 for GWP and 2-4 for AP failed normality tests. The remaining clusters displayed normal distributions. Levene's results showed that all groups violated the null hypothesis, pointing to heterogeneous variances between groups. GWP and AP Welch t-test means comparison were rejected because of the skewed distributions of some of their clusters. This means that $50 \%$ of the data is not comparable according to this statistical protocol due to non-normal distributions. The means comparisons were validated for EP and CED. The test revealed statistically significant differences of the means between the clusters of $\operatorname{EP}(p=0.004)$ but no differences were found between the clusters' means of CED $(p=0.066)$. Post hoc Games-Howell test identified the statistical difference within EP to be between clusters 1-2, 3-4, and 2-4. It means that overall, only significant differences were identified for EP between closed, sea-based and open, land-based systems $(p=0.030)$, between open, sea-based and closed, land-based systems $(p=0.012)$, as well as open, land-based and closed, land-based systems $(p=0.006)$. For the four FCR groups (Figure 1), each cluster validated the condition of normality and results showed clear heterogeneity of variances $(p=0.0001)$. The null-hypothesis of Welch was rejected $(p=0.023)$ indicating a significant difference between at least two of the clusters' means. Post hoc testing indicated that the difference was lying between cluster 2-3 ( $p=0.009$; open, land-based and open, sea-based systems) while the remaining of the clusters had statistically equal means (see supplementary data, Sections 3.3.2.1 and 3.3.2.2).

\section{(b) Two-Groups Analysis}

Two two-group analyses were performed on both LCIA and FCR data. One was testing the data of sea-based (cluster A) vs. land-based (cluster B) studies while the other was testing open (cluster C) vs. closed (cluster D) systems. Each two-group LCIA analysis consists of eight clusters while each FCR one consists of two (Figure 1). Cluster A-B for GWP, B for AP, and A for EP failed the normality test. Homogeneity of variances was observed in AP and EP while the null hypothesis was rejected for GWP and CED. GWP, AP, and EP ANOVA and Welch means comparisons were rejected due to skewness in at least one of their clusters. This means that $75 \%$ of the data could not be tested and interpreted. The Welch t-test mean comparison for CED was accepted, showing significant differences between the means of closed, sea-based and open, land-based clusters for this impact category $(p=0.01)$. All clusters failed normality, except cluster D for EP in the open vs. closed data comparison. Levene's test demonstrated that clusters of GWP, EP, and CED had heterogenous variances while AP clusters displayed a homogeneous one. Since seven out of the eight clusters were skewed, results of both ANOVA and Welch t-tests were rejected. In this case, 100\% of the data was rejected and could not be compared using this statistical protocol (see supplementary data, Sections 3.3.2.3 and 3.3.2.4). The FCR data of clusters A-B confirm the null hypothesis of Shapiro-Wilk, supporting that both samples are distributed normally. The same results could be observed for the FCR data of clusters C and D. Also, both A-B (sea-based and land-based) groups and C-D (open and closed) systems displayed heterogeneous variances. In the A-B comparison, the null hypothesis of Welch was rejected $(p=0.021)$, demonstrating a significant difference between the means of sea-based and land-based clusters. Opposite results were found for the C-D comparison $(p=0.654)$; open and closed 
systems FCR means were not statistically different from each other (Section 3.3.2.5, "FCR two-group stat. A-B", and Section 3.3.2.6, "FCR two-group stat. C-D", supplementary data).

\section{Discussion}

\subsection{Methodologies}

The methodological variations identified in this LCA review are understandable considering the difficulty of developing a "one size fits all" LCA methodology for production systems that differ in time, space, and structure. Overall, the results showed relatively consistent FU and system boundaries but displayed variations in the way LCA practitioners deal with multi-functionality and LCIA. These variations were not necessarily negative since methods selections were often case-specific, determined by the scope of the study, and could also be driven by methodological developments. Keeping this flexibility enables practitioners to adapt the method to the production system instead of the opposite. However, method customization should not be achieved at the expense of clarity. For instance, for impact category selection, it is essential to cover the main environmental impacts of the system while also limiting the number of categories to keep the results comprehensible for readers. This issue is discussed in Steinmann et al. [80], who found that within current impact categories, seven indicators were estimated to cover $92 \%$ of the variance of product rankings from the Ecoinvent database (based on 976 products). It means that by selecting GWP, land use, ozone depletion, AP, $\mathrm{EP}$, marine, and terrestrial ecotoxicity, the practitioner covers nearly the entire spectrum of impacts at the midpoint level. The authors also suggest using RACER (relevant, accepted, credible, easy, robust) criteria to refine the indicator selection, as well as encourage the use of regionalized impact categories [80]. Based on Steinmann's perspective and the categories selection rates in salmonid LCA, we recommend practitioners assessing such aquaculture systems to concentrate primarily on: (1) GWP, (2) $\mathrm{EP}$, (3) AP, (4) CED, (5) marine ecotoxicity, (6) terrestrial ecotoxicity, and (7) land-use. Biotic resource use and water use are also of interest, depending on the scope of the study. However, while these established impact categories are adapted to measure impacts of product and services, they are not necessarily well equipped for production technology comparison. The development of aquaculture specific impact categories is long wished for in the literature $[40,50,54,58]$ and suggestions to include local ecological impacts have already been made years ago [81]. In this perspective, accounting for the impacts of aquaculture on biodiversity and water quality suggested by Ford et al. [81] would significantly improve the environmental criteria by which we compare the different types of salmonid aquaculture production systems.

There is an overall lack of innovative methodological integration in LCA of salmonids production systems (Table 3). For instance, it is unclear why several recent publications $[27,54,57]$ continue to apply characterization factors from CML $2001[68,82,83]$ when new (and more comprehensive) indicators are available in ReCiPe [72,84,85]. Lack of comprehensive and standardized methodological reporting is another shortcoming of the current literature. For example, since no rules exist for including and reporting contribution, sensitivity, and uncertainty analyses, the quantity and quality of information provided by LCA practitioners vary widely. While contribution analysis is commonly disclosed in LCA studies (although not always in numerical terms), the inclusion of uncertainty analysis remains rare. In this review, only one out of five LCIA results were calculated with an uncertainty range (Table 3). Systematic uncertainty assessments would benefit the comparisons conducted in this paper. The lack of overall methodological description is a challenge for replicability, transparency, and review. For instance, gathering the detailed characterization factors used for each impact category was complicated by the overall lack of data description (both in articles and supplementary data). We recommend that LCA practitioners pursue a flexible application of the LCA methodology to best suit each study's scope. It should entail considering the latest methodological LCA developments (when relevant) and going further than the LCA guidelines provided by the ISO framework [86] using, for instance, the procedure developed by the European Research Commission [87]. However, this adaptive 
application of LCA necessitates detailed and systematic reporting to be fully exploitable (reproducible and comparable) by the research community. It is therefore critical that researchers document their LCA methodological choices extensively, especially in the supplementary data. We recommend practitioners to systematically disclose and argue for major modeling decisions (e.g., characterization factors) and assumptions (e.g., cut-off criteria) performed under their assessment.

\subsection{Inventories}

In both trout and salmon LCA studies, process completeness is directly influenced by the FU and system boundaries selection (e.g., hatchery, processing, distribution), by the choice of impact categories (e.g., effluent), by the type of technology studied (e.g., effluent treatment), and by the scope of the research (e.g., infrastructure EOL). The inclusion of equipment and infrastructure is lower in salmon LCI, which could be explained by the "light-weight" of open sea-based cages compared to RAS and FTAS systems, more frequently used in trout production. The inclusion of chemotherapeutic agents appears more frequently for trout than salmon ( $55 \%$ and $23 \%$, respectively). This could be due to the importance of water quality treatments (input of oxygen, limestone, and other chemicals) in FTAS and RAS production systems. Often the exclusion of processes such as chemotherapeutants, equipment, infrastructure, and egg production is based on the assumption that those processes have an overall low contribution $[35,54,55]$. Since process-based LCA remains resource intensive to conduct, practitioners often choose to perform such cut-offs, especially if data availability is low and/or quality poor. Interpreting the importance of such processes (when accounted for) is also challenging due to their variable definitions across studies. For instance, several authors include the production of salmonid eggs in their inventory $[27,28,33,50]$, but the specific nature of this process remains uncertain because detailed descriptions are lacking. Considering the growing biological challenges faced by open sea-based salmon production [88,89], accounting for the environmental impacts of parasites and diseases treatments is becoming a necessity. So far only three of the 13 salmon LCAs reviewed accounted for a form of chemotherapeutant use (antibiotics and water quality treatments), and only for closed land-based production phases (hatcheries using FTAS or RAS systems) [32,34,57]. The frequent salmon lice sea-based treatments using biological (cleaner fish), chemical (baths and feed), and mechanical (primarily warm-water baths) processes remain unaccounted for in current LCAs. In Norway, use of cleaner fish requires aquaculture and fisheries activities dedicated to produce and capture Lumpfish (Cyclopterus lumpus) and various species of Wrasses (Labridae). The value-chains involved are complex and require significant use of marine ingredient rich aquafeed to produce the cleaner fish and sustain them throughout the salmon production cycle. Overall, the use of chemicals is following a descending trend, mainly because of sea-lice resistances. Yet, the use of hydrogen peroxide and other substances like azamethiphos and cypermethrin in baths remain commonly used, generating unquantified marine ecotoxicity impacts. In addition, the use of both mechanical and chemical delousing treatments has proven deleterious effects on farmed salmon mortality [90]. It is essential to determine how much direct and indirect impacts are linked to these various types of delousing treatments, especially when we know that in recent years, mortality represented between $6-9 \%$ of the total Norwegian production in terms of biomass [91].

Overall, inventories also suffer from limitations similar to those from the methodologies: Incomplete description and partial disclosure. While data confidentiality can explain why portions of the inventory cannot be fully disclosed, we still think process description and data reporting can be largely improved. Good research practices could consist to systematically disclose foreground systems, including the sources, time, and place of data collection. More descriptions of the production systems are also required. It would increase transparency and enable more subsequent analyses based on this data. Pelletier et al. [31] and White [59] are two good examples of how inventory data can efficiently be presented. When confidentiality is a requirement from companies, authors should work closely with the data provider to share a maximum of data while still safeguarding sensitive information. Aggregating inventory inputs can be one way to do so. 
Another issue identified in this review concerns data representativity. Although most studies report collecting first-hand data for the most crucial processes (feed and grow-out), a significant fraction of the datasets are built with recycled data from previous studies. For example, the feed dataset developed in Pelletier and Tyedmers [92] and Pelletier et al. [31] was reportedly used in six subsequent salmonid LCAs, primarily because of its completeness (high representativity), availability (supplementary data), and perceived quality (highly cited paper). A few years ago, Henriksson et al. [93] suggested a protocol for the horizontal averaging of foreground and background data, accounting for data uncertainty generated by inaccurate measurement and means variability. This protocol is one of the tools LCA practitioners can use to circumvent cross-referencing of obsolete data. There is also a lack of open data on salmonid feed ingredients and the production processes of aquafeed, especially since it is estimated central for salmonid LCA to use data representative of the feed used. Substantial inclusion of an analog dataset tends to artificially increase the level of diversity and completeness (more case studies tested with similar data) of a given research area and reduces variability between studies. The construction of national inventories and open LCA databases is crucial to address these issues, and it has already been recommended in an aquaculture LCA review published so far [37,39]. We, therefore, recommend LCA practitioners to support the development of open inventories such as AGRYBALYSE [94], the Seafood LCI database [95], or the Thai LCI database [96]. We also suggest researchers to participate more actively in the GFLI (Global Feed LCA Institute) initiative and collaborate with the FEFAC (European Feed Manufacturers' Federation) to access to the latest data.

It can also be highlighted that the extensive use of case studies in salmonid LCAs (and the broader field of LCA) are not always well equipped to fully capture the environmental impacts of large production value-chains such as aquaculture. In salmonid LCA, data collection is limited in time (a production cycle) and often limited in space (one production site). Exceptions consisting of Chen et al. [28], Papatryphon et al. [24], Pelletier et al. [31], Ziegler et al. [48], and White [59] who covered significant proportions of the national productions they analyzed (global production in the case of Pelletier et al. [31]). Process-based LCA is well tailored to compare specific production parameters, sites, technology, or products, but is not optimized to achieve process completeness or to model whole sectors of an economy. Using environmental input-output models could address these issues by providing process completeness and resolution to national aquaculture sectors. Research to develop successful hybrid input-output/LCA models have been taking place for several years [97,98] and the recent development of EXIOBASE v3 [99] and its incorporations in a hybridized framework is promising [100,101]. In practice, this could be done by replacing conventional LCA background processes by data from the multi-regional supply and use input-output databases. Not only could such frameworks account for side processes usually left out of process-based LCA (e.g., office activities, bank transactions, labor), but it could also allow practitioners to integrate processes with low inclusion levels such as chemotherapeutants, equipment, infrastructure, egg production, as well as the whole upper value-chain (processing and distribution). Unsurprisingly, this method will also bring its load of challenges. Among others, LCA practitioners will likely have more difficulties to disaggregate processes, work at local or regional scales, and choose restrictive system boundaries.

\subsection{Cross-study Technological Comparison}

\subsubsection{Outlying Results}

Large intra-cluster differences observed throughout the four impact categories are due to the variable nature of production systems studied and of LCA methodology applied. Although we review similar species using standardized system boundaries and FU, LCAs are performed on specific systems, using different feed regimes, varying in time and space, and calculated with adaptive LCA methodology. This inevitably generates significant discrepancies. Yet, if we analyze the outlying results for each impact category, individual studies can be identified, and their extreme scores can be linked to methodological choices, specific inventory, or other particularities. Salmon impacts 
from Ayer and Tyedmers [34], White [59], and Parker [57] display consistently high outstanding impacts while d'Orbcastel et al. [53], Grönroos et al. [36], Nyhus [56], and Dekamin et al. [54] report much lower impacts for trout production. Samuel-Fitwi et al. [50] generated both fringe high and low scores depending on the impact category considered. In Ayer and Tyedmers [34] the inventory shows that both the FTAS and RAS scenario report elevated electricity consumption $(13,400 \mathrm{kWh}$ and $22,600 \mathrm{kWh}$, respectively). This high demand coupled to the Canadian electricity mix (61\% hydro, $18 \%$ coal, $13 \%$ nuclear, $4 \%$ oil, and $4 \%$ natural gas) leads to unusually high impacts for GWP and AP (Figure 4; Figure 5). Parker [57] and White [59] studied the environmental impacts of Tasmanian salmon, commonly fed with high inclusion of animal by-products from fisheries, poultry, as well as mammals like swine and beef cattle. In these studies, the higher impacts from the feed composition are accentuated by high FCR levels (1.3 and 1.46). These factors combined explain the remarkably high GWP, AP, EP, and CED scores of these two studies. The borderline high results obtained by Samuel-Fitwi et al. [50] in GWP and AP are directly linked to the high electricity demand of the system $(19,622 \mathrm{kWh})$ and the high percentage of fossil fuels in the electricity mix of the region. In fact, by replacing this mix by wind power, the RAS GWP impacts are cut by a factor of 10 [50]. The reasons for the outlaying low scores for EP and CED remain uncertain. The authors report nearly zero nutrient emissions thanks to the mechanical and biological filtration systems, yet such filters are not a unique component of this study. The significant differences between attributional and consequential LCA frameworks could explain some of these differences. Rainbow trout LCA studies appear to generate most of the extreme low values across both technology clusters and impact categories (Figures 4-7). d'Orbcastel et al. [53] reported consistently low impacts, especially for the hypothetical RAS scenario displaying a low FCR and high fish density throughout production. The hypothetical nature of this production system and the reuse of fish slurry as biofertilizer could explain these outlier results. While the corrected data provided by the author [102] somewhat leveled the differences between Grönroos et al. [36] and other studies, this assessment still reports some of the lowest scores for the closed sea-based and open sea-based clusters AP. The significant difference with the other studies remains uncertain, but we suspect the lower AP scores to be linked to outdated data (1987 to 2000), to the feed composition, which was largely based on fish meal at this time, and potentially the use of Finnish characterization factors. Similarly to d'Orbcastel et al. [53], Dekamin et al. [54] report low GWP and AP scores for the FTAS scenario and a low EP for the RAS system. In the latter, water outlet is treated by drum and bio-filters as well as ion exchange, which could explain nutrient emissions as low as 8.5 PO4-e. Based on the contribution analysis, the low GWP and AP are due to an advantageous FCR and low electricity requirement [54].

\subsubsection{Cross-Study Statistical Comparison}

Although a significant portion of the LCIA statistical analysis was rejected, the current data state allowed us to perform some statistical comparisons of clusters means on both LCIA and FCR data. In the LCIA four-group analysis we statistically demonstrated that the clusters mean were similar for CED, which means that there was no statistical evidence that CED of salmonids production systems was varying in pair with the production technologies. Yet, by increasing the sample size of the comparison in the two-group LCIA A-B analysis we demonstrated that sea-based and land-based production technologies correlated with CED impacts. This means that on average, sea-based outperformed land-based systems for this impact category ( 41,768 vs. $96,771 \mathrm{MJ}-\mathrm{e})$. Such results have been repeatedly observed in the literature, where land-based systems generally demonstrated to have higher energy consumption due to the land-based water circulation requirements $[34,36,51,60]$. There is also evidence that clusters 1-2, 3-4, and 2-4 display statistically different EP scores. It means that on average closed sea-based outperform open land-based systems (26.7 kg vs. 50.6 PO4-e), closed land-based outperformed open sea-based systems (17.3 vs. 47.3 PO4-e), and closed land-based outperform open land-based systems (17.3 vs. $50.6 \mathrm{~kg}$ PO4-e; Figure 6). While there were strong indications that EP impacts correlate with the open and closed characteristics of productions systems, this was not strictly 
demonstrated since EP impacts of clusters 1-3 have equal means and the results of the two-group LCIA C-D analysis were rejected due to skewness. These results were also coherent with the scientific literature since open systems have no waste collection, and therefore emit more nutrients into the environment than their closed counterparts [42].

All the FCR data qualified for statistical analysis. This suggests that FCR data is less sensitive to some confounding factors since it is an inventory parameter and not a multivariable computed LCIA result. In the four-group FCR analysis, we demonstrated that cluster 2-3 have statistically different means while all the other cluster comparisons did not. It means that on average, open land-based outperform open sea-based systems (1.124 vs. 1.256) for the FCR. The technological characteristic determinant for this difference is identified in the two-group FCR A-B and C-D analyses, once the sample size has been expanded. The A-B comparison shows that the sea-based or land-based traits of the systems were responsible for this difference while the C-D analysis proved that the open or closed characteristic did not influence the results. Overall, it means that land-based systems have lower FCR than sea-based systems on average (1.124 vs. 1.257). We hypothesize that this significant difference is due to the more controlled environment unique to land-based facilities. At sea, salmonids are exposed to fluctuating seasonal temperatures, parasites, and latent or active disease outbreaks. These dynamic factors invariably lead to less predictable feeding, and mortality discrepancies, which directly affects the FCR of sea-systems negatively.

\subsubsection{Data Quality for Meta-Analysis}

One of the clear outcomes of the statistical analysis performed on LCIA and FCR data, is the bottleneck generated by the poor meta-data quality available from LCAs of salmonids. While it certainly exists other statistical protocols one could have used to compare the means of different clusters in various groups, the statistical tests we applied were selected for their robustness, simplicity and recognized comparative properties across scientific fields [103-105]. We observed that 50\% of the LCIA four-group, $75 \%$ of the LCIA two-group A-B, and $100 \%$ of the LCIA two-group C-D analyses were rejected due to the skewness of the data. Small sample sizes, data skewness, variability of distributions, and the multitude of confounding factors existing between studies represent a major limitation for such statistical meta-analysis. Increasing the scope of the comparison may improve sample sizes and distributions but it will inevitably reinforce influences of confounding factors. To improve the potential of cross-study results comparison in LCA, we identify two main levers. The first one consists of significantly increasing the quantities of LCA studies available per commodities to increase sample sizes and statistical power required for more robust statistical comparisons. Today, the inertia of LCA studies are such that for certain commodities, only a few case-studies are published sporadically through time. Process-based LCA analyses are expensive to conduct and often require several months of data collection, often largely depending on the voluntary participation of companies. This bottleneck could be partially addressed using hybridized IO-LCA methodology (see 4.2. "Inventories") to model more efficiently background systems. It could also be tackled by means of direct access to data streams from production systems, reducing drastically time and resources applied to collect data manually from companies. The quantity of data collected by companies is increasing exponentially, and the adoption of industry 4.0 (automated manufacturing using connected sensors) could drastically increase the speed and ease of access to data [106]. Such a technological revolution could also allow practitioners to perform LCA on digital twins of production systems to enable various forms of prospective environmental assessments. The second lever should provide the tools to enable full reproducibility. This implies re-thinking in-depth the current LCA methodology. Reaching full reproducibility would require major changes in LCA practices. Today, LCA reproducibility is drastically limited by data ownership, poor data availability, limited disclosure practices (see 4.1. "Methodologies" and 4.2. "Inventories"), and restrictive software licenses. To alleviate confounding factors limiting cross-study comparisons without using a strictly standardized LCA framework for all systems, practitioners need access to the full inventory in the LCA software. With direct access to the LCA 
models, it would be much more feasible for researchers to verify, reproduce, and modify LCAs for comparative purposes. This off-course raises issues since desegregated foreground data is usually subject to confidentiality agreements with companies, background data is subject to access to LCA databases (e.g., Ecoinvent), and most popular LCA software (e.g., SimaPro, Gabi) are licensed. A way around these challenges could consist to provide incentives for open data and open software (e.g., OpenLCA) and favorize the publications of LCAs in open access journals. Monetary data is freely open in most countries and represent one development lead. Open LCA databases are valuable initiative requiring more development (see 4.2. "Inventories"). Finally, a third alternative to democratize open data could be achieved by national manufacturing reporting schemes managed by governmental entities. For instance, in Norway, the aquaculture industry is required to report some production data (e.g., biomass produced, mortality, feed use, etc.) to the Directorate of Fisheries regularly. Such data is compiled and made available for stakeholders. With the emergence of industry 4.0, efficient data collection, and data transfer, one could imagine that authorities could collect detailed production data from companies to dynamically monitor the environmental impacts of the commodities they are producing. Emerging technologies such as distributed ledger technology could also be an integral part of such systems to certify that the data provided by the manufacturer has not been modified or tampered with $[107,108]$.

\section{Conclusions}

Throughout our analyses, the idea that LCA practitioners should strive to achieve systematic reporting rather than looking for a single and standard way to apply LCA on salmonid aquaculture systems was strengthened. Using balanced levels of methodological flexibility gives researchers the freedom they need to adapt the methodology to their production system and specific goals, thereby allowing methodological innovation without compromising minimum requirements of comparability. Systematic reporting of methodological choices and inventory data is an essential comparability requirement currently lacking in the reviewed literature. We, therefore, urge LCA researchers to disclose their methodology and their foreground system inventory in their supplementary data. Such practices will facilitate future attempts to conduct reviews, but more importantly, it would allow the scientific community to access, analyze, adapt, compare, and reuse data for other purposes. Journal editors are in a position to make sure authors comply by enforcing full data and methods transparency as part of their publication requirements.

The lack of process and methodology completeness is another pitfall we identified across the literature. While sensitivity and uncertainty analyses are not required to perform an ISO-compliant LCA, these are essential research tools to measure uncertainty surrounding data, methodological choices or assumptions, and to identify the critical environmental hot spots of a system. Still, often authors omitted sensitivity and uncertainty analyses and excluded processes on uncertain basis. Although we cannot expect LCA practitioners to reach $100 \%$ completeness using process-based LCA, there is room for improvements. For instance, we expect current disease and parasite treatments performed on salmonid open sea-based systems, activities that to date have been excluded, to give significant contributions to total impacts.

Our first attempt to do a cross-study analysis based on salmonid LCA demonstrates two main results. Firstly, although the data quality remains weak, it proves possible to perform single factor comparisons across studies despite confounding factors. We were able to compare some of the data statistically and, based on differences measured, rank specific clusters according to their average EP, CED, and FCR scores. Secondly, we demonstrated that such meta-analyses are limited by the current state of LCA methods and data. To improve salmonid LCA cross-study comparison, researchers should thrive on increasing the quantity and reproducibility of LCA data and on making sure that LCA methodological developments lead towards more data availability for stakeholders. We believe that investigating the meta-analysis potential of LCA is critical for methodological progress, and more importantly, to drive sustainable development of products and services. Influencing the sustainability 
of production sectors through research is a challenging task for which isolated, highly specific environmental assessments are not necessarily well suited for. Industrial actors and policymakers need robust research-based information, built on overarching trends, to be able to make sustainable strategic choices for the future.

Supplementary Materials: The following are available online at http://www.mdpi.com/2071-1050/11/9/2517/s1.

Author Contributions: Conceptualization G.P., F.Z. and A.S.; Data curation G.P.; Formal Analysis G.P., M.D.J.; Funding acquisition (not applicable); Investigation G.P.; Methodology G.P., F.Z., L.C.G., M.D.J., E.O.G. and A.S.; Project administration G.P.; Resources (not applicable); Software (not application); Supervision F.Z., L.C.G., M.D.J. and A.S.; Validation L.C.G. and F.Z.; Visualization G.P.; Writing—original draft G.P.; Writing一review \& editing G.P., F.Z., L.C.G., M.D.J., E.O.G. and A.S.

Funding: This research received no external funding.

Acknowledgments: We would like to sincerely thank Frans Silvenius and Richard Newton for taking the time to collect and share additional data with us.

Conflicts of Interest: The authors declare no conflict of interest.

\section{References}

1. Food and Agriculture Organization (FAO). The State of World Fisheries and Aquaculture 2018-Meeting the Sustainable Development Goals; Food and Agriculture Organization of the United Nations: Rome, Italy, 2018.

2. United Nations. World Population Prospects: The 2017 Revision, Key Findings and Advance Tables; United Nations, Department of Economic and Social Affairs, Population Division: New York, NY, USA, 2017.

3. Wu, G.Y.; Fanzo, J.; Miller, D.D.; Pingali, P.; Post, M.; Steiner, J.L.; Thalacker-Mercer, A.E. Production and supply of high-quality food protein for human consumption: Sustainability, challenges, and innovations. Ann. N. Y. Acad. Sci. 2014, 1321, 1-19. [CrossRef]

4. Tilman, D.; Clark, M. Global diets link environmental sustainability and human health. Nature 2014, 515, 518 . [CrossRef]

5. Crist, E.; Mora, C.; Engelman, R. The interaction of human population, food production, and biodiversity protection. Science 2017, 356, 260-264. [CrossRef]

6. Steffen, W.; Richardson, K.; Rockström, J.; Cornell, S.E.; Fetzer, I.; Bennett, E.M.; Biggs, R.; Carpenter, S.R.; De Vries, W.; de Wit, C.A. Planetary boundaries: Guiding human development on a changing planet. Science 2015, 347, 736-747. [CrossRef] [PubMed]

7. Food and Agriculture Organization (FAO). The State of World Fisheries and Aquaculture 2016-Contributing to Food Security and Nutrition for All; Food and Agriculture Organization of the United Nations: Rome, Italy, 2016.

8. Dickie, A.; Streck, C.; Roe, S.; Zurek, M.; Haupt, F.; Dolginow, A. Strategies for Mitigating Climate Change in Agriculture: Recommendations for Philanthropy; Focus and California Environmental Associates, Prepared with the Support of the Climate and Land Use Alliance: San Francisco, CA, USA, 2014.

9. Xiao, Z.; Ximing, C. Climate change impacts on global agricultural land availability. Environ. Res. Lett. 2011, 6, 014014. [CrossRef]

10. Kobayashi, M.; Msangi, S.; Batka, M.; Vannuccini, S.; Dey, M.M.; Anderson, J.L. Fish to 2030: The role and opportunity for aquaculture. Aquac. Econ. Manag. 2015, 19, 282-300. [CrossRef]

11. Food and Agriculture Organization (FAO). Globfish-Information and Analysis on World Fish Trade. Available online: http://www.fao.org/in-action/globefish/market-reports/resource-detail/en/c/1176223/ (accessed on 29 March 2019).

12. Farmer, L.J.; McConnell, J.M.; Kilpatrick, D.J. Sensory characteristics of farmed and wild Atlantic salmon. Aquaculture 2000, 187, 105-125. [CrossRef]

13. Sprague, M.; Dick, J.R.; Tocher, D.R. Impact of sustainable feeds on omega-3 long-chain fatty acid levels in farmed Atlantic salmon, 2006-2015. Sci. Rep. 2016, 6, 21892. [CrossRef] [PubMed]

14. Hilborn, R.; Banobi, J.; Hall Stephen, J.; Pucylowski, T.; Walsworth Timothy, E. The environmental cost of animal source foods. Front. Ecol. Env. 2018, 16, 329-335. [CrossRef]

15. Nijdam, D.; Rood, T.; Westhoek, H. The price of protein: Review of land use and carbon footprints from life cycle assessments of animal food products and their substitutes. Food Policy 2012, 37, 760-770. [CrossRef] 
16. Ellerby, D.J. How efficient is a fish? J. Exp. Biol. 2010, 213, 3765-3767. [CrossRef]

17. Ytrestøyl, T.; Aas, T.S.; Åsgård, T. Resource Utilisation of Norwegian Salmon Farming in 2012 and 2013; Nofima: Tromsø, Norway, 2014.

18. Mennerat, A.; Nilsen, F.; Ebert, D.; Skorping, A. Intensive Farming: Evolutionary Implications for Parasites and Pathogens. J. Evol. Biol. 2010, 37, 59-67. [CrossRef]

19. Gracey, E. MFA of Omega-3 Fatty Acids EPA \& DHA from a Norwegian Resource Perspective. Master's Thesis, Norwegian University of Science and Technology, Trondheim, Norway, 2014.

20. Philis, G.; Gracey, E.O.; Gansel, L.C.; Fet, A.M.; Rebours, C. Comparing the primary energy and phosphorus consumption of soybean and seaweed-based aquafeed proteins-A material and substance flow analysis. J. Clean. Prod. 2018, 200, 1142-1153. [CrossRef]

21. Meld. St. 16. Forutsigbar og Miljømessig Bærekraftig Vekst i Norsk Lakse-og Ørretoppdrett. Available online: https://www.regjeringen.no/contentassets/6d27616f18af458aa930f4db9492fbe5/no/pdfs/ stm201420150016000dddpdfs.pdf (accessed on 12 September 2019).

22. Jonell, M.; Henriksson, P.J.G. Mangrove-shrimp farms in Vietnam-Comparing organic and conventional systems using life cycle assessment. Aquaculture 2015, 447, 66-75. [CrossRef]

23. Jerbi, M.; Aubin, J.; Garnaoui, K.; Achour, L.; Kacem, A. Life cycle assessment (LCA) of two rearing techniques of sea bass (Dicentrarchus labrax). Aquac. Eng. 2012, 46, 1-9. [CrossRef]

24. Papatryphon, E.; Petit, J.; Van der Werf, H.; Kaushik, S.; Saint-Pée-sur-Nivelle, F. Life Cycle Assessment of trout farming in France: A farm level approach. In Proceedings of the 4th International Conference, Life Cycle Assessment in the Agri-food sector, Bygholm, Denmark, 6-8 October 2003; DIAS Foulum: Tjele, Denmark, 2004; pp. 71-77.

25. Ellingsen, H.; Aanondsen, S.A. Environmental impacts of wild caught cod and farmed Salmon-A comparison with chicken (7 pp). Int. J. Life Cycle Assess. 2006, 11, 60-65. [CrossRef]

26. Fréon, P.; Durand, H.; Avadí, A.; Huaranca, S.; Orozco Moreyra, R. Life cycle assessment of three Peruvian fishmeal plants: Toward a cleaner production. J. Clean. Prod. 2017, 145, 50-63. [CrossRef]

27. Smarason, B.O.; Ogmundarson, O.; Arnason, J.; Bjornsdottir, R.; Daviosdottir, B. Life Cycle Assessment of Icelandic Arctic Char Fed Three Different Feed Types. Turk. J. Fish Aquat. Sci. 2017, 17, 79-90. [CrossRef]

28. Chen, X.; Samson, E.; Tocqueville, A.; Aubin, J. Environmental assessment of trout farming in France by life cycle assessment: Using bootstrapped principal component analysis to better define system classification. J. Clean. Prod. 2015, 87, 87-95. [CrossRef]

29. Boissy, J.; Aubin, J.; Drissi, A.; van der Werf, H.M.G.; Bell, G.J.; Kaushik, S.J. Environmental impacts of plant-based salmonid diets at feed and farm scales. Aquaculture 2011, 321, 61-70. [CrossRef]

30. Avadí, A.; Pelletier, N.; Aubin, J.; Ralite, S.; Núñez, J.; Fréon, P. Comparative environmental performance of artisanal and commercial feed use in Peruvian freshwater aquaculture. Aquaculture 2015, 435, 52-66. [CrossRef]

31. Pelletier, N.; Tyedmers, P.; Sonesson, U.; Scholz, A.; Ziegler, F.; Flysjo, A.; Kruse, S.; Cancino, B.; Silverman, H. Not all salmon are created equal: Life cycle assessment (LCA) of global salmon farming systems. Environ. Sci. Technol. 2009, 43, 8730-8736. [CrossRef]

32. Hognes, E.S.; Nilsson, K.; Sund, V.; Ziegler, F. LCA of Norwegian Salmon Production 2012; Sintef Fisheries and Aquaculture: Trondheim, Norway, 2014.

33. McGrath, K.P.; Pelletier, N.L.; Tyedmers, P.H. Life Cycle Assessment of a Novel Closed-Containment Salmon Aquaculture Technology. Environ. Sci. Technol. 2015, 49, 5628-5636. [CrossRef]

34. Ayer, N.W.; Tyedmers, P.H. Assessing alternative aquaculture technologies: Life cycle assessment of salmonid culture systems in Canada. J. Clean. Prod. 2009, 17, 362-373. [CrossRef]

35. Liu, Y.; Rosten, T.W.; Henriksen, K.; Hognes, E.S.; Summerfelt, S.; Vinci, B. Comparative economic performance and carbon footprint of two farming models for producing Atlantic salmon (Salmo salar): Land-based closed containment system in freshwater and open net pen in seawater. Aquac. Eng. 2016, 71, 1-12. [CrossRef]

36. Grönroos, J.; Seppala, J.; Silvenius, F.; Makinen, T. Life cycle assessment of Finnish cultivated rainbow trout. Boreal Environ. Res. 2006, 11, 401.

37. Henriksson, P.J.G.; Guinee, J.B.; Kleijn, R.; de Snoo, G.R. Life cycle assessment of aquaculture systems-A review of methodologies. Int. J. Life Cycle Assess. 2012, 17, 304-313. [CrossRef]

38. Aubin, J. Life cycle assessment as applied to environmental choices regarding farmed or wild-caught fish. CAB Rev. Perspect. Agric. Vet. Sci. Nutr. Nat. Resour. 2013, 8. [CrossRef] 
39. Bohnes, F.A.; Laurent, A. LCA of aquaculture systems: Methodological issues and potential improvements. Int. J. Life Cycle Assess. 2018, 24, 324-337. [CrossRef]

40. Cao, L.; Diana, J.S.; Keoleian, G.A. Role of life cycle assessment in sustainable aquaculture. Rev. Aquac. 2013, 5, 61-71. [CrossRef]

41. Henriksson, P.J.G.; Pelletier, N.L.; Troell, M.; Tyedmers, P.H. Life Cycle Assessments and Their Applications to Aquaculture Production Systems life cycle assessment (LCA) aquaculture production systems. In Sustainable Food Production; Christou, P., Savin, R., Costa-Pierce, B.A., Misztal, I., Whitelaw, C.B.A., Eds.; Springer: New York, NY, USA, 2013; pp. 1050-1066.

42. Pahri, S.D.R.; Mohamed, A.F.; Samat, A. LCA for open systems: A review of the influence of natural and anthropogenic factors on aquaculture systems. Int. J. Life Cycle Assess. 2015, 20, 1324-1337. [CrossRef]

43. Bohnes, F.A.; Hauschild, M.Z.; Schlundt, J.; Laurent, A. Life cycle assessments of aquaculture systems: A critical review of reported findings with recommendations for policy and system development. Rev. Aquac. 2018, 24, 324-337. [CrossRef]

44. Buchspies, B.; Tölle, S.J.; Jungbluth, N. Life Cycle Assessment of High-Sea Fish and Salmon Aquaculture; ESU-Services Ltd.: Uster, Switzerland, 2011.

45. Ytrestøyl, T.; Aas, T.; Berge, G.; Hatlen, B.; Sørensen, M.; Ruyter, B.; Thomassen, M.; Hognes, E.; Ziegler, F.; Sund, V. Resource Utilisation and Eco-Efficiency of Norwegian Salmon Farming in 2010; Nofima: Tromsø, Norway, 2011.

46. Hall, S.J.; Delaporte, A.; Phillips, J.M.; Malcolm, B.; Mark, O.K. Blue Frontiers: Managing the Environmental Costs of Aquaculture; The WorldFish Center: Penang, Malaysia, 2011.

47. Winther, U.; Ziegler, F.; Hognes, E.S.; Emanuelsson, A.; Sund, V.; Ellingsen, H. Carbon Footprint and Energy Use of Norwegian Seafood Products; Sintef Fisheries and Aquaculture: Trondheim, Norway, 2009.

48. Ziegler, F.; Winther, U.; Hognes, E.S.; Emanuelsson, A.; Sund, V.; Ellingsen, H. The carbon footprint of Norwegian seafood products on the global seafood market. J. Ind. Ecol. 2013, 17, 103-116. [CrossRef]

49. Samuel-Fitwi, B.; Schroeder, J.P.; Schulz, C. System delimitation in life cycle assessment (LCA) of aquaculture: Striving for valid and comprehensive environmental assessment using rainbow trout farming as a case study. Int. J. Life Cycle Assess. 2013, 18, 577-589. [CrossRef]

50. Samuel-Fitwi, B.; Nagel, F.; Meyer, S.; Schroeder, J.P.; Schulz, C. Comparative life cycle assessment (LCA) of raising rainbow trout (Oncorhynchus mykiss) in different production systems. Aquac. Eng. 2013, 54, 85-92. [CrossRef]

51. Aubin, J.; Papatryphon, E.; van der Werf, H.M.G.; Chatzifotis, S. Assessment of the environmental impact of carnivorous finfish production systems using life cycle assessment. J. Clean. Prod. 2009, 17, 354-361. [CrossRef]

52. Ayer, N.; Martin, S.; Dwyer, R.L.; Gace, L.; Laurin, L. Environmental performance of copper-alloy Net-pens: Life cycle assessment of Atlantic salmon grow-out in copper-alloy and nylon net-pens. Aquaculture 2016, 453, 93-103. [CrossRef]

53. d'Orbcastel, E.R.; Blancheton, J.-P.; Aubin, J. Towards environmentally sustainable aquaculture: Comparison between two trout farming systems using Life Cycle Assessment. Aquac. Eng. 2009, 40, 113-119. [CrossRef]

54. Dekamin, M.; Veisi, H.; Safari, E.; Liaghati, H.; Khoshbakht, K.; Dekamin, M.G. Life cycle assessment for rainbow trout (Oncorhynchus mykiss) production systems: A case study for Iran. J. Clean. Prod. 2015, 91, 43-55. [CrossRef]

55. Newton, R.W.; Little, D.C. Mapping the impacts of farmed Scottish salmon from a life cycle perspective. Int. J. Life Cycle Assess. 2017, 23, 1018-1029. [CrossRef]

56. Nyhus, O.J. Life Cycle Assessment of Farmed Salmon, Comparing a Closed with an Open Sea Cage System. Master's Thesis, Norwegian University of Science and Technology, Trondheim, Norway, 2014.

57. Parker, R. Implications of high animal by-product feed inputs in life cycle assessments of farmed Atlantic salmon. Int. J. Life Cycle Assess. 2017, 23, 982-994. [CrossRef]

58. Silvenius, F.; Grönroos, J.; Kankainen, M.; Kurppa, S.; Mäkinen, T.; Vielma, J. Impact of feed raw material to climate and eutrophication impacts of Finnish rainbow trout farming and comparisons on climate impact and eutrophication between farmed and wild fish. J. Clean. Prod. 2017, 164, 1467-1473. [CrossRef]

59. White, A. A Comprehensive Analysis of Efficiency in the Tasmanian Salmon Industry. Ph.D. Thesis, Bond University, Gold Coast, Australia, 2013. 
60. Wilfart, A.; Prudhomme, J.; Blancheton, J.-P.; Aubin, J. LCA and emergy accounting of aquaculture systems: Towards ecological intensification. J. Environ. Manag. 2013, 121, 96-109. [CrossRef]

61. Fry, J.P.; Mailloux, N.A.; Love, D.C.; Milli, M.C.; Cao, L. Feed conversion efficiency in aquaculture: Do we measure it correctly? Environ. Res. Lett. 2018, 13, 024017. [CrossRef]

62. Tlusty, M.; Tyedmers, P.; Ziegler, F.; Jonell, M.; Henriksson, P.J.; Newton, R.; Little, D.; Fry, J.; Love, D.; Cao, L. Commentary: Comparing efficiency in aquatic and terrestrial animal production systems. Environ. Res. Lett. 2018, 13, 128001. [CrossRef]

63. Fornshell, G.; Hinshaw, J.; Tidwell, J.H. Flow-through Raceways. In Aquaculture Production Systems; Tidwell, J.H., Ed.; John Wiley \& Sons, Inc.: Lexington, KY, USA, 2012.

64. Langan, R. Ocean Cage Culture. In Aquaculture Production Systems; Tidwell, J.H., Ed.; John Wiley \& Sons, Inc.: Lexington, KY, USA, 2012.

65. Ebeling, J.M.; Timmons, M.B. Recirculating Aquaculture Systems. In Aquaculture Production Systems; Tidwell, J.H., Ed.; John Wiley \& Sons, Inc.: Lexington, KY, USA, 2012.

66. ISO 14040:2006. Environmental Management_Life Cycle Assessment_Principles and Framework, 2nd ed.; The International Standards Organization: Geneva, Switzerland, 2006.

67. Intergovernmental Panel on Climate Change (IPCC). Climate Change 2007: The Physical Science Basis; Contribution of Working Group I to the Fourth Assessment Report of the Intergovernmental Panel on Climate Change; Solomon, S., Qin, D., Manning, M., Chen, Z., Marquis, M., Averyt, K.B., Tignor, M., Miller, H.L., Eds.; Cambridge University Press: New York, NY, USA, 2007; p. 996.

68. Heijungs, R.; Guinée, J.B.; Huppes, G.; Lankreijer, R.M.; Udo de Haes, H.A.; Wegener Sleeswijk, A.; Ansems, A.; Eggels, P.; Duin, R.v.; De Goede, H. Environmental Life Cycle Assessment of Products: Guide and Backgrounds (Part 1); Centre of Environmental Science: Leiden, The Netherlands, 1992.

69. Huijbregts, M. Life-Cycle Impact Assessment of Acidifying and Eutrophying Air Pollutants. Calculation of Equivalency Factors with RAINS-LCA; Faculty of Environmental Science, University of Amsterdam: Amsterdam, The Netherlands, 1999.

70. Frischknecht, R.; Jungbluth, N.; Althaus, H.; Doka, G.; Dones, R.; Hirschier, R.; Hellweg, S.; Humbert, S.; Margni, M.; Nemecek, T.; et al. Implementation of Life Cycle Impact Assessment Methods; Swiss Centre for LCI: Duebendorf, Switzerland, 2003.

71. Frischknecht, R.; Jungbluth, N.; Althaus, H.-J.; Hischier, R.; Doka, G.; Bauer, C.; Dones, R.; Nemecek, T.; Hellweg, S.; Humbert, S. Implementation of Life Cycle Impact Assessment Methods; Data v2. 0 (2007); Ecoinvent Report No. 3; Ecoinvent Centre: Duebendorf, Switzerland, 2007.

72. Hauschild, M.; Potting, J. Spatial Differentiation in Life Cycle Impact Assessment-The EDIP2003 Methodology; Technical University of Denmark: Kongens Lyngby, Denmark, 2005.

73. Thrane, M. Environmental Impacts from Danish Fish Products; Aalborg University: Aalborg, Denmark, 2004.

74. Schau, E.M.; Fet, A.M. LCA studies of food products as background for environmental product declarations. Int. J. Life Cycle Assess. 2008, 13, 255-264. [CrossRef]

75. Vázquez-Rowe, I.; Moreira, M.T.; Feijoo, G. Life cycle assessment of horse mackerel fisheries in Galicia (NW Spain): Comparative analysis of two major fishing methods. Fish. Res. 2010, 106, 517-527. [CrossRef]

76. Thrane, M. LCA of Danish fish products-New methods and insights. Int. J. Life Cycle Assess. 2006, 11, 66-74. [CrossRef]

77. Tyedmers, P. Energy consumed by North Atlantic fisheries. Fisheries Centre Research Reports. In Fisheries Impacts on North Atlantic Ecosystems: Catch, Effort and National/Regional Datasets; Zeller, D., Watson, R., Pauly, D., Eds.; Fisheries Centre, University of British Columbia: Vancouver, BC, Canada, 2001.

78. Cashion, T.; Tyedmers, P.; Parker, R.W. Global reduction fisheries and their products in the context of sustainable limits. Fish Fish. 2017, 18, 1026-1037. [CrossRef]

79. Parker, R.W.; Tyedmers, P.H. Fuel consumption of global fishing fleets: Current understanding and knowledge gaps. Fish Fish. 2015, 16, 684-696. [CrossRef]

80. Steinmann, Z.J.N.; Schipper, A.M.; Hauck, M.; Huijbregts, M.A.J. How Many Environmental Impact Indicators Are Needed in the Evaluation of Product Life Cycles? Environ. Sci. Technol. 2016, 50, 3913-3919. [CrossRef]

81. Ford, J.S.; Pelletier, N.L.; Ziegler, F.; Scholz, A.J.; Tyedmers, P.H.; Sonesson, U.; Kruse, S.A.; Silverman, H. Proposed Local Ecological Impact Categories and Indicators for Life Cycle Assessment of Aquaculture A Salmon Aquaculture Case Study. J. Ind. Ecol. 2012, 16, 254-265. [CrossRef] 
82. Huijbregts, M.; Thissen, U.; Guinée, J.; Jager, T.; Kalf, D.; Van de Meent, D.; Ragas, A.; Sleeswijk, A.W.; Reijnders, L. Priority assessment of toxic substances in life cycle assessment. Part I: Calculation of toxicity potentials for 181 substances with the nested multi-media fate, exposure and effects model USES-LCA. Chemosphere 2000, 41, 541-573. [CrossRef]

83. Huijbregts, M.A.; Schöpp, W.; Verkuijlen, E.; Heijungs, R.; Reijnders, L. Spatially Explicit Characterization of Acidifying and Eutrophying Air Pollution in Life-Cycle Assessment. J. Ind. Ecol. 2000, 4, 75-92. [CrossRef]

84. Van Zelm, R.; Huijbregts, M.A.; Van Jaarsveld, H.A.; Reinds, G.J.; De Zwart, D.; Struijs, J.; Van de Meent, D. Time horizon dependent characterization factors for acidification in life-cycle assessment based on forest plant species occurrence in Europe. Environ. Sci. Technol. 2007, 41, 922-927. [CrossRef] [PubMed]

85. Rosenbaum, R.K.; Bachmann, T.M.; Gold, L.S.; Huijbregts, M.A.; Jolliet, O.; Juraske, R.; Koehler, A.; Larsen, H.F.; MacLeod, M.; Margni, M. USEtox-The UNEP-SETAC toxicity model: Recommended characterisation factors for human toxicity and freshwater ecotoxicity in life cycle impact assessment. Int. J. Life Cycle Assess. 2008, 13, 532. [CrossRef]

86. ISO 14044:2006. Environmental Management_Life Cycle Assessment-Requirements and Guidelines, 1st ed.; The International Standards Organization: Geneva, Switzerland, 2006.

87. ILCD Handbook. General Guide for Life Cycle Assessment, Detailed Guidance; European Commission, Joint Research Centre: Luxembourg, 2010.

88. Pettersen, J.; Osmundsen, T.; Aunsmo, A.; Mardones, F.; Rich, K. Controlling emerging infectious diseases in salmon aquaculture. Rev. Sci. Tech. Off. Int. Epiz. 2015, 34, 923-938. [CrossRef]

89. Taranger, G.L.; Karlsen, Ø.; Bannister, R.J.; Glover, K.A.; Husa, V.; Karlsbakk, E.; Kvamme, B.O.; Boxaspen, K.K.; Bjørn, P.A.; Finstad, B. Risk assessment of the environmental impact of Norwegian Atlantic salmon farming. ICES J. Mar. Sci. 2014, 72, 997-1021. [CrossRef]

90. Overton, K.; Dempster, T.; Oppedal, F.; Kristiansen, T.S.; Gismervik, K.; Stien, L.H. Salmon lice treatments and salmon mortality in Norwegian aquaculture: A review. Rev. Aquac. 2018. [CrossRef]

91. BarentsWarch. Fish Mortality and Loss in Production. 2018. Available online: https://www.barentswatch.no/ en/havbruk/fish-mortality-and-loss-in-production (accessed on 22 March 2019).

92. Pelletier, N.; Tyedmers, P. Feeding farmed salmon: Is organic better? Aquaculture 2007, 272, $399-416$. [CrossRef]

93. Henriksson, P.J.G.; Guinée, J.B.; Heijungs, R.; de Koning, A.; Green, D.M. A protocol for horizontal averaging of unit process data-Including estimates for uncertainty. Int. J. Life Cycle Assess. 2014, 19, 429-436. [CrossRef]

94. Colomb, V.; Ait-Amar, S.; Basset-Mens, C.; Gac, A.; Gaillard, G.; Koch, P.; Mousset, J.; Salou, T.; Tailleur, A.; Van Der Werf, H.M. AGRIBALYSE ${ }^{\circledR}$, the French LCI Database for Agricultural Products: High Quality Data for Producers and Environmental Labelling. Oilseeds Fats Crop. Lipids 2015, 22, D104. [CrossRef]

95. Hognes, E.S.; Tyedmers, P.; Krewer, C.; Scholten, J.; Ziegler, F. Seafood Life Cycle Inventory Database—Methodology and Principles and Data Quality Guidelines; RISE Agrifood and Bioscience: Göteborg, Sweden, 2018.

96. Chomkhamsri, K.; Mungcharoen, T.; Yuvaniyama, C. 10-year experience with the Thai national LCI database: Case study of "refinery products". Int. J. Life Cycle Assess. 2017, 22, 1760-1770. [CrossRef]

97. Hawkins, T.; Hendrickson, C.; Higgins, C.; Matthews, H.S.; Suh, S. A mixed-unit input-output model for environmental life-cycle assessment and material flow analysis. Environ. Sci. Technol. 2007, 41, 1024-1031. [CrossRef]

98. Majeau-Bettez, G.; Strømman, A.H.; Hertwich, E.G. Evaluation of process-and input-output-based life cycle inventory data with regard to truncation and aggregation issues. Environ. Sci. Technol. 2011, 45, 10170-10177. [CrossRef]

99. Merciai, S.; Schmidt, J. Methodology for the construction of global multi-regional hybrid supply and use tables for the EXIOBASE v3 database. J. Ind. Ecol. 2018, 22, 516-531. [CrossRef]

100. Gibon, T.; Wood, R.; Arvesen, A.; Bergesen, J.D.; Suh, S.; Hertwich, E.G. A methodology for integrated, multiregional life cycle assessment scenarios under large-scale technological change. Environ. Sci. Technol. 2015, 49, 11218-11226. [CrossRef]

101. Hertwich, E.G.; Gibon, T.; Bouman, E.A.; Arvesen, A.; Suh, S.; Heath, G.A.; Bergesen, J.D.; Ramirez, A.; Vega, M.I.; Shi, L. Integrated life-cycle assessment of electricity-supply scenarios confirms global environmental benefit of low-carbon technologies. Proc. Natl. Acad. Sci. USA 2015, 112, 6277-6282. [CrossRef]

102. Silvenius, F.; (Luke, Natural Resources Institute, Helsinki, Finland). Personal communication, 2 March 2019. 
103. Park, H.M. Comparing Group Means: T-Tests and One-Way ANOVA Using Stata, SAS, R, and SPSS. Ph.D. Thesis, Indiana University, Bloomington, IN, USA, 2009.

104. Kim, H.-Y. Analysis of variance (ANOVA) comparing means of more than two groups. Restor. Dent. Endod. 2014, 39, 74-77. [CrossRef]

105. Ruxton, G.D. The unequal variance t-test is an underused alternative to Student's t-test and the Mann-Whitney U test. Behav. Ecol. 2006, 17, 688-690. [CrossRef]

106. Lee, J.; Kao, H.-A.; Yang, S. Service Innovation and Smart Analytics for Industry 4.0 and Big Data Environment. Procedia CIRP 2014, 16, 3-8. [CrossRef]

107. Kouhizadeh, M.; Sarkis, J. Blockchain Practices, Potentials, and Perspectives in Greening Supply Chains. Sustainability 2018, 10, 3652. [CrossRef]

108. Weidema, B.; Klarmann, M. What Will Distributed Ledger Technology Mean for LCA? Available online: https://lca-net.com/blog/what-will-distributed-ledger-technology-mean-for-lca/ (accessed on 18 March 2019).

(C) 2019 by the authors. Licensee MDPI, Basel, Switzerland. This article is an open access article distributed under the terms and conditions of the Creative Commons Attribution (CC BY) license (http://creativecommons.org/licenses/by/4.0/). 